\title{
Spinochrome D Attenuates Doxorubicin-Induced Cardiomyocyte Death via Improving Glutathione Metabolism and Attenuating Oxidative Stress
}

\author{
Chang Shin Yoon ${ }^{1}{ }^{\oplus}$, Hyoung Kyu Kim ${ }^{1}$, Natalia P. Mishchenko ${ }^{2}{ }^{\mathbb{D}}$, Elena A. Vasileva ${ }^{2}$, \\ Sergey A. Fedoreyev ${ }^{2}$, Valentin A. Stonik ${ }^{2}$ and Jin Han ${ }^{1, *}$ \\ 1 National Research Laboratory for Mitochondrial Signaling, Department of Physiology, College of Medicine, \\ Cardiovascular and Metabolic Disease Center (CMDC), Inje University, Busan 614-735, Korea; \\ changshin73@gmail.com (C.S.Y.); estrus74@gmail.com (H.K.K.) \\ 2 G.B. Elyakov Pacific Institute of Bioorganic Chemistry, Far-Eastern Branch of the Russian Academy of \\ Science, Vladivostok 690022, Russia; mischenkonp@mail.ru (N.P.M.); vasilieva_el_an@mail.ru (E.A.V.); \\ fedoreev-s@mail.ru (S.A.F.); stonik@piboc.dvo.ru (V.A.S.) \\ * Correspondence: phyhanj@inje.ac.kr; Tel.: +82-51-890-6727; Fax: +82-51-894-5714
}

Received: 28 November 2018; Accepted: 15 December 2018; Published: 20 December 2018

\begin{abstract}
Doxorubicin, an anthracycline from Streptomyces peucetius, exhibits antitumor activity against various cancers. However, doxorubicin is cardiotoxic at cumulative doses, causing increases in intracellular reactive oxygen species in the heart. Spinochrome D $(\mathrm{SpD})$ has a structure of 2,3,5,6,8-pentahydroxy-1,4-naphthoquinone and is a structural analogue of well-known sea urchin pigment echinochrome A. We previously reported that echinochrome A is cardioprotective against doxorubicin toxicity. In the present study, we assessed the cardioprotective effects of SpD against doxorubicin and determined the underlying mechanism. ${ }^{1} \mathrm{H}-\mathrm{NMR}$-based metabolomics and mass spectrometry-based proteomics were utilized to characterize the metabolites and proteins induced by $\mathrm{SpD}$ in a human cardiomyocyte cell line (AC16) and human breast cancer cell line (MCF-7). Multivariate analyses identified 12 discriminating metabolites (variable importance in projection > 1.0) and 1814 proteins from SpD-treated AC16 cells. Proteomics and metabolomics analyses showed that glutathione metabolism was significantly influenced by SpD treatment in AC16 cells. SpD treatment increased ATP production and the oxygen consumption rate in D-galactose-treated AC16 cells. SpD protected AC16 cells from doxorubicin cytotoxicity, but it did not affect the anticancer properties. With SpD treatment, the mitochondrial membrane potential and mitochondrial calcium localization were significantly different between cardiomyocytes and cancer cell lines. Our findings suggest that $\mathrm{SpD}$ could be cardioprotective against the cytotoxicity of doxorubicin.
\end{abstract}

Keywords: Spinochrome D; doxorubicin; cardioprotective effect

\section{Introduction}

Echinochrome A has a chemical structure of 6-ethyl-2,3,5,7,8-pentahydroxy-1,4-naphthoquinone, which exhibits cardioprotective activity and reduces the myocardial ischemia/reperfusion injury via its antioxidant effect and enhancement of mitochondria biogenesis [1-3]. Echinochrome A has a number of structural analogues and together they comprise the class of spinochrome pigments of sea urchins. Biological effects of spinochromes were investigated mainly on crude extracts [4] and there is not so much information on the activity of individual pigments, particularly regarding cardioprotective ability. Spinochrome $\mathrm{D}(\mathrm{SpD})$ is one of six main spinochromes and it is biosynthesized by many sea urchin species (Figure 1A) [5]. SpD is a side product of echinochrome A isolation from the flat sea urchin Scaphechinus mirabilis, which is utilized for the preparation of the active substance 
of the antioxidant and the cardioprotective drug Histochrome ${ }^{\circledR}$ [6]. Nevertheless, the content of SpD in sea urchins is usually pretty low (0.001-0.003\% of dry weight), but recently by Balaneva et al. was developed a simple and effective synthesis scheme with the yield of SpD in 58\% [7]. SpD might be assumed to inherit the cardioprotective ability of echinochrome A, but the detailed mechanism has been unknown.<smiles>O=C1C(O)=C(O)C(=O)c2c(O)c(O)cc(O)c21</smiles>

(A)

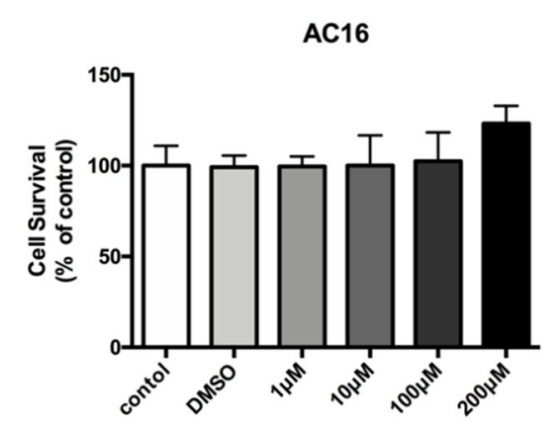

(B)

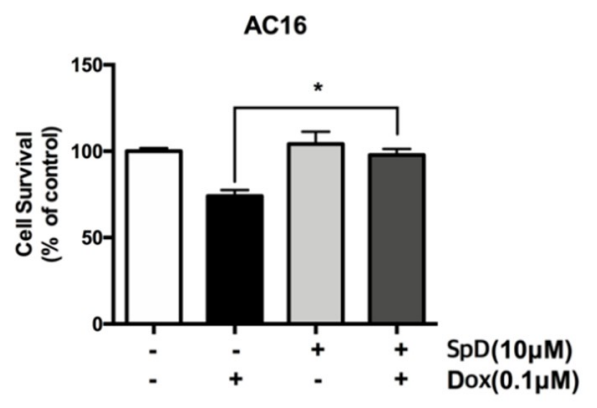

(C)

Figure 1. Spinochrome D $(\mathrm{SpD})$ protected cardiac cells from the cytotoxicity of doxorubicin. (A) Chemical structure of SpD (MW, 238.15044); (B) AC16 human cardiomyocytes were treated with 0-200 $\mu \mathrm{M}$ SpD for $24 \mathrm{~h}$ and cell viability was measured using a Cell Counting Kit-8 reagent (CCK-8) assay. SpD did not affect the cell viability of cardiomyocytes. ${ }^{*} p<0.05$ compared with control; (C) Treatment with SpD $(10 \mu \mathrm{M}, 24 \mathrm{~h})$ attenuated the cardiotoxicity of doxorubicin $(0.1 \mu \mathrm{M})$ in AC16 cells.

Doxorubicin is an anthracycline that was firstly extracted from Streptomyces peucetius and it has been routinely used for the treatment of several cancers, including breast, lung, gastric, ovarian, non-Hodgkin's, and Hodgkin's lymphoma [8,9]. There are several proposed anti-cancer mechanisms of doxorubicin, including intercalation into DNA and generation of reactive oxygen species (ROS). The inhibition of topoisomerase II has been known to induce apoptosis in cells [10-12].

Unfortunately, cumulative dose of doxorubicin over $550 \mathrm{mg} / \mathrm{m}^{2}$ body surface area has been known to develop cardiomyopathy $[13,14]$. The exact mechanism of cardiomyopathy is still controversial but iron-related free radical formation and mitochondrial disruption have been considered to be the main causes [15]. There have been trials to overcome the doxorubicin's cardiac toxicity by reducing its oxygen radical formation to achieve important accomplishment [16-18].

In the present study, we demonstrated that SpD has a cardio-protective effect against the cardiac toxicity of doxorubicin without interfering the cytotoxicity to cancer cell lines. We used an integration of ${ }^{1} \mathrm{H}-\mathrm{NMR}$ based metabolomics and mass-spectrometry based proteomics to specify molecular pathways that are affected by SpD treatment in human cardiomyocytes. We also measured changes of the mitochondrial membrane potential and mitochondrial calcium in $\mathrm{SpD}$ treated human cardiomyocytes.

\section{Results}

\subsection{SpD Protected AC16 Cells against Doxorubicin Cytotoxicity}

Human cardiomyocyte AC16 cells were treated with SpD at 1-200 $\mu \mathrm{M}$ (Figure 1B). We found no harmful effects on cell viability. Identical concentrations of $\mathrm{SpD}$ were tested on rat cardiomyocyte 
H9c2 cells and also they showed no effect on cell viability (Figure S1). The cell viability of AC16 cells decreased after $0.1 \mu \mathrm{M}$ doxorubicin treatment for $24 \mathrm{~h}$, and an exposure duration of $48 \mathrm{~h}$ resulted in cell death for the majority of cells (data not shown). However, adding $10 \mu \mathrm{M} \mathrm{SpD}$ treatment in addition to doxorubicin for $24 \mathrm{~h}$ led to $80-90 \%$ AC16 cell survival (Figure 1C).

\subsection{Liquid Chromatography-Mass Spectrometry-MS (LC-MS/MS)-Based Proteomics Analyses of SpD/Doxorubicin-Treated AC16 Cells}

We performed LC-MS/MS analysis of cell lysates from SpD-treated and -untreated AC16 cells with or without doxorubicin for $24 \mathrm{~h}$. The detected proteins are shown in Venn diagrams (Figure 2A,B) and full lists (Supplementary Information 2). We found networks of proteins forming clusters that are centered on "mitochondria" (Figure 2C and Figure S5). The affected pathways based on the Kyoto Encyclopedia of Genes and Genomes (KEGG) database listed proteins participating in gap junction, focal adhesion, aminoacyl-tRNA biosynthesis, and glutathione metabolism (Figure 2D).

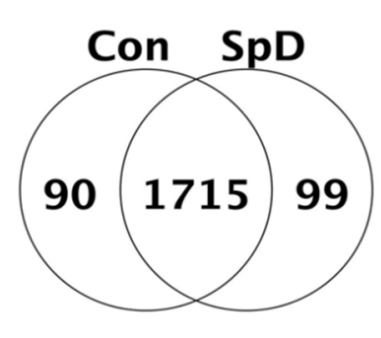

(A)

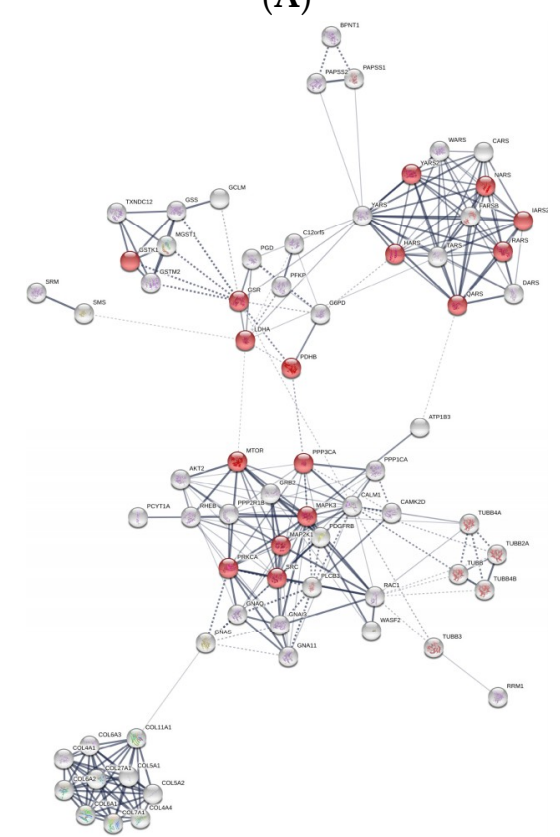

(C)

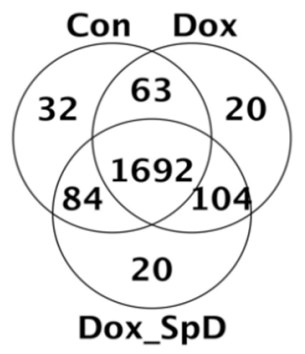

(B)

KEGG pathway from STRING analysis

\begin{tabular}{lcc}
\hline \multicolumn{1}{c}{ pathway } & Observed gene count & FDR \\
& & \\
\hline & 16 & $1.47 \times 10^{-21}$ \\
Gap junction & 18 & $1.81 \times 10^{-18}$ \\
Focal adhesion & 12 & $2.22 \times 10^{-18}$ \\
Aminoacyl-tRNA biosynthesis & 12 & $9.83 \times 10^{-18}$ \\
Glutathione metabolism & 19 & $3.06 \times 10^{-16}$ \\
PI3K-Akt signaling pathway & 12 & $7.29 \times 10^{-15}$ \\
Protein digestion and absorption & 11 & $5.04 \times 10^{-13}$ \\
GnRH signaling pathway & 12 & $8.39 \times 10^{-13}$ \\
Platelet activation & 12 & $2.68 \times 10^{-12}$ \\
Adrenergic signaling in cardiomyocytes & 11 & $2.68 \times 10^{-12}$ \\
Amoebiasis & & \\
\hline
\end{tabular}

(D)

Figure 2. Mass spectrometry-based proteomics of SpD-treated AC16 cells. Liquid Chromatography-Mass Spectrometry-MS (LC-MS/MS) spectrometry-based proteomics detected proteins from SpD (10 $\mu \mathrm{M}, 24 \mathrm{~h})$ (A) and SpD/doxorubicin (B) treated AC16 cells; (C) Search Tool for the Retrieval of Interacting Genes/Proteins (STRING) analysis showed that altered metabolic proteins clustered around "mitochondria" which are represented as red colored nodes. All filled nodes represent the 3D structures of proteins are known; and, (D) The top 10 influenced metabolic pathways are shown from the STRING analysis (Kyoto Encyclopedia of Genes and Genomes (KEGG) database). 


\section{3. ${ }^{1} \mathrm{H}$-NMR Mediated Metabolomics Analysis of SpD-Treated AC16 Cells}

To identify metabolite alterations that are induced by $\mathrm{SpD}$, we used ${ }^{1} \mathrm{H}-\mathrm{NMR}$ spectroscopy to characterize $30 \mathrm{mg}$ of AC16 cells incubated with $\mathrm{SpD}(10 \mu \mathrm{M})$ for $24 \mathrm{~h}$. Metabolic profiling (Chenomx, Edmonton, AB, Canada) was used to identify 32 metabolites in SpD-treated AC16 cells and untreated control cells (Table 1).

Table 1. Identified metabolites and their corresponding concentrations (mM; mean, standard deviation), as determined by Chenomx NMR Suit $7.1^{\circledR}$ peak fitting of individual ${ }^{1} \mathrm{H}-\mathrm{NMR}$ spectra $(600 \mathrm{MHz})$ for $\mathrm{SpD}(10 \mu \mathrm{M})$ treated AC16 cells (30 mg, $n=3)$.

\begin{tabular}{|c|c|c|c|c|}
\hline \multirow{2}{*}{ Metabolite } & \multicolumn{2}{|c|}{ Control } & \multicolumn{2}{|c|}{ SpD } \\
\hline & Mean (mM) & S.D. & Mean (mM) & S.D. \\
\hline Acetate & 8.218 & 5.815 & 4.820 & 1.541 \\
\hline Alanine & 1.236 & 0.665 & 1.341 & 0.315 \\
\hline Asparagine & 0.388 & 0.194 & 0.397 & 0.095 \\
\hline Aspartate & 0.412 & 0.139 & 0.428 & 0.138 \\
\hline Choline & 0.751 & 0.437 & 0.831 & 0.111 \\
\hline Creatine & 0.463 & 0.190 & 0.557 & 0.051 \\
\hline Formate & 0.230 & 0.034 & 0.197 & 0.048 \\
\hline Fumarate & 0.143 & 0.047 & 0.164 & 0.043 \\
\hline Glutamate & 2.877 & 1.640 & 3.622 & 0.791 \\
\hline Glutamine & 0.129 & 0.048 & 0.101 & 0.006 \\
\hline Glutathione & 0.383 & 0.158 & 0.572 & 0.081 \\
\hline Glycerol & 0.912 & 0.405 & 0.788 & 0.088 \\
\hline Glycine & 1.650 & 0.952 & 1.900 & 0.656 \\
\hline Hypoxanthine & 0.285 & 0.222 & 0.349 & 0.089 \\
\hline Inosine & 0.169 & 0.068 & 0.209 & 0.056 \\
\hline Isoleucine & 0.169 & 0.080 & 0.235 & 0.031 \\
\hline Lactate & 9.551 & 3.793 & 12.374 & 2.715 \\
\hline Leucine & 0.829 & 0.536 & 0.824 & 0.073 \\
\hline Lysine & 0.783 & 0.489 & 0.719 & 0.124 \\
\hline Methionine & 0.064 & 0.017 & 0.090 & 0.029 \\
\hline O-Phosphocholine & 0.274 & 0.124 & 0.392 & 0.066 \\
\hline O-Phosphoethanolamine & 0.939 & 0.468 & 1.068 & 0.091 \\
\hline Phenylalanine & 0.376 & 0.200 & 0.364 & 0.018 \\
\hline Proline & 0.907 & 0.435 & 1.114 & 0.202 \\
\hline Serine & 0.948 & 0.536 & 0.790 & 0.352 \\
\hline Taurine & 0.505 & 0.270 & 0.723 & 0.198 \\
\hline Threonine & 0.853 & 0.434 & 0.846 & 0.152 \\
\hline Tyrosine & 0.323 & 0.168 & 0.329 & 0.004 \\
\hline Uracil & 0.363 & 0.243 & 0.279 & 0.021 \\
\hline Valine & 0.479 & 0.272 & 0.474 & 0.073 \\
\hline myo-Inositol & 1.198 & 0.554 & 1.750 & 0.352 \\
\hline sn-Glycero-3-phosphocholine (GPC) & 0.123 & 0.058 & 0.245 & 0.068 \\
\hline
\end{tabular}

After normalization of the data (Figure 3), univariate and multivariate statistical analyses were used to comprehensively evaluate the effects of SpD on AC16 cells. 
Before Normalization
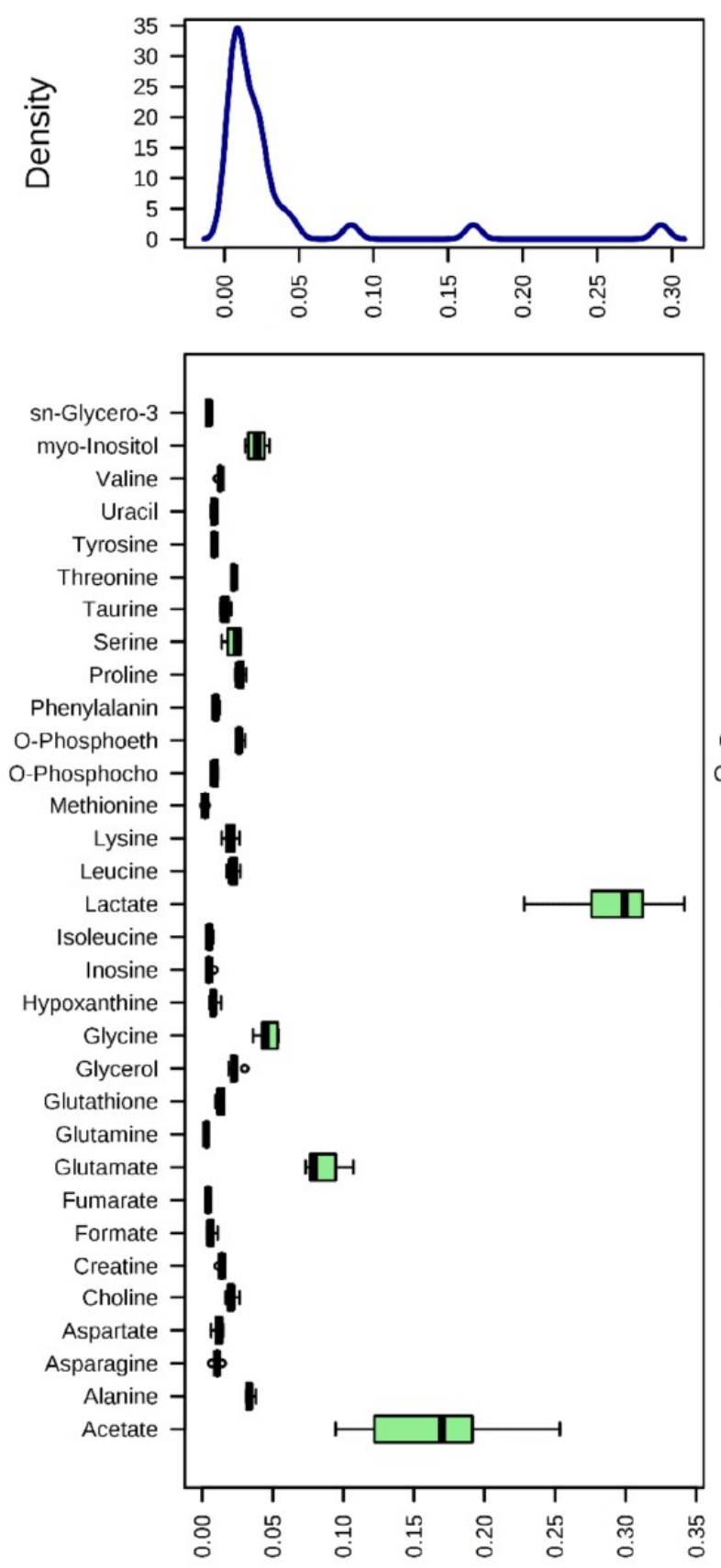

Concentration
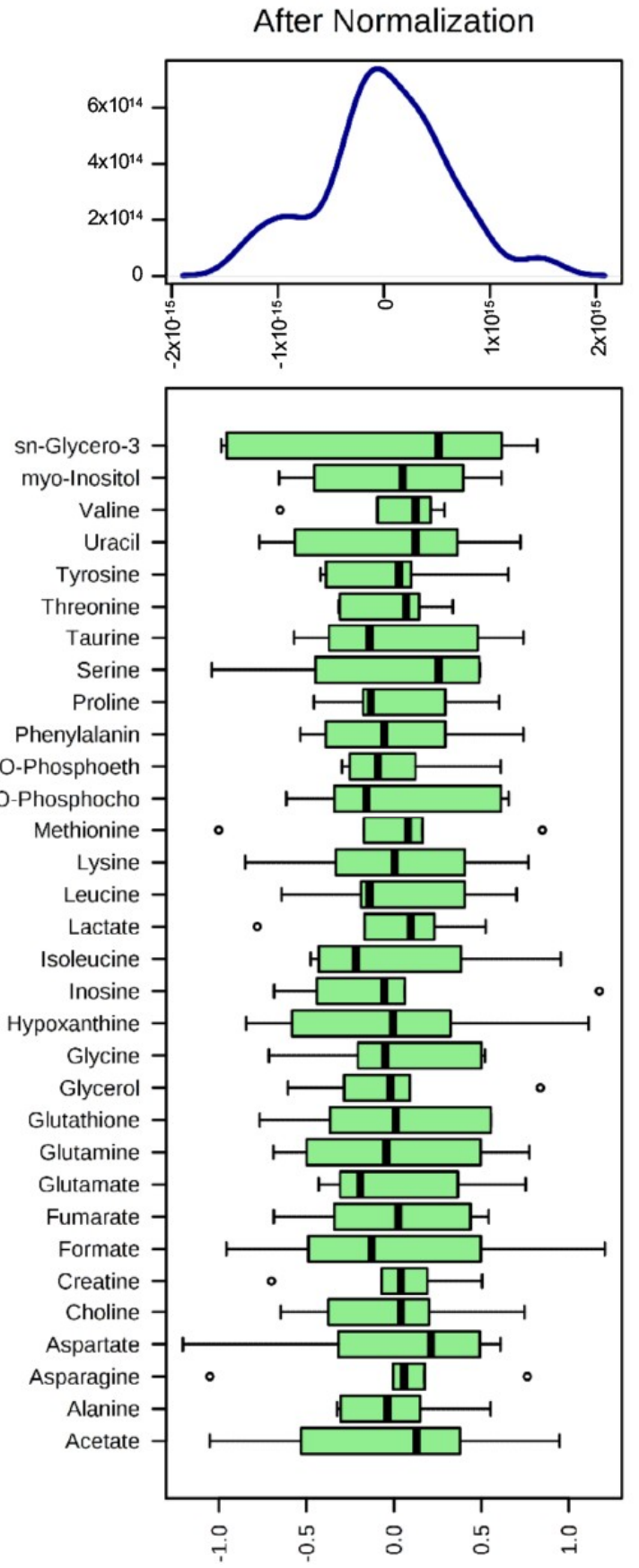

Normalized Concentration

Figure 3. Normalization of ${ }^{1} \mathrm{H}-\mathrm{NMR}$ aquired metabolite concentrations. The concentrations of metabolites were normalized by log-transformation followed by Pareto scaling (mean-centered and divided by the square root of the standard deviation of each variable). Changes of metabolites are represented as ratios of control metabolites.

Univariate volcano plots of $\log 2(\mathrm{FC})>1.2(p<0.05)$ metabolites showed that the levels of sn-glycero-3-phosphocholine (GPC), glutathione, myo-inositol, taurine, and O-phosphocholine were increased, while the levels of acetate and glutamine were decreased, by SpD (Figure 4). 


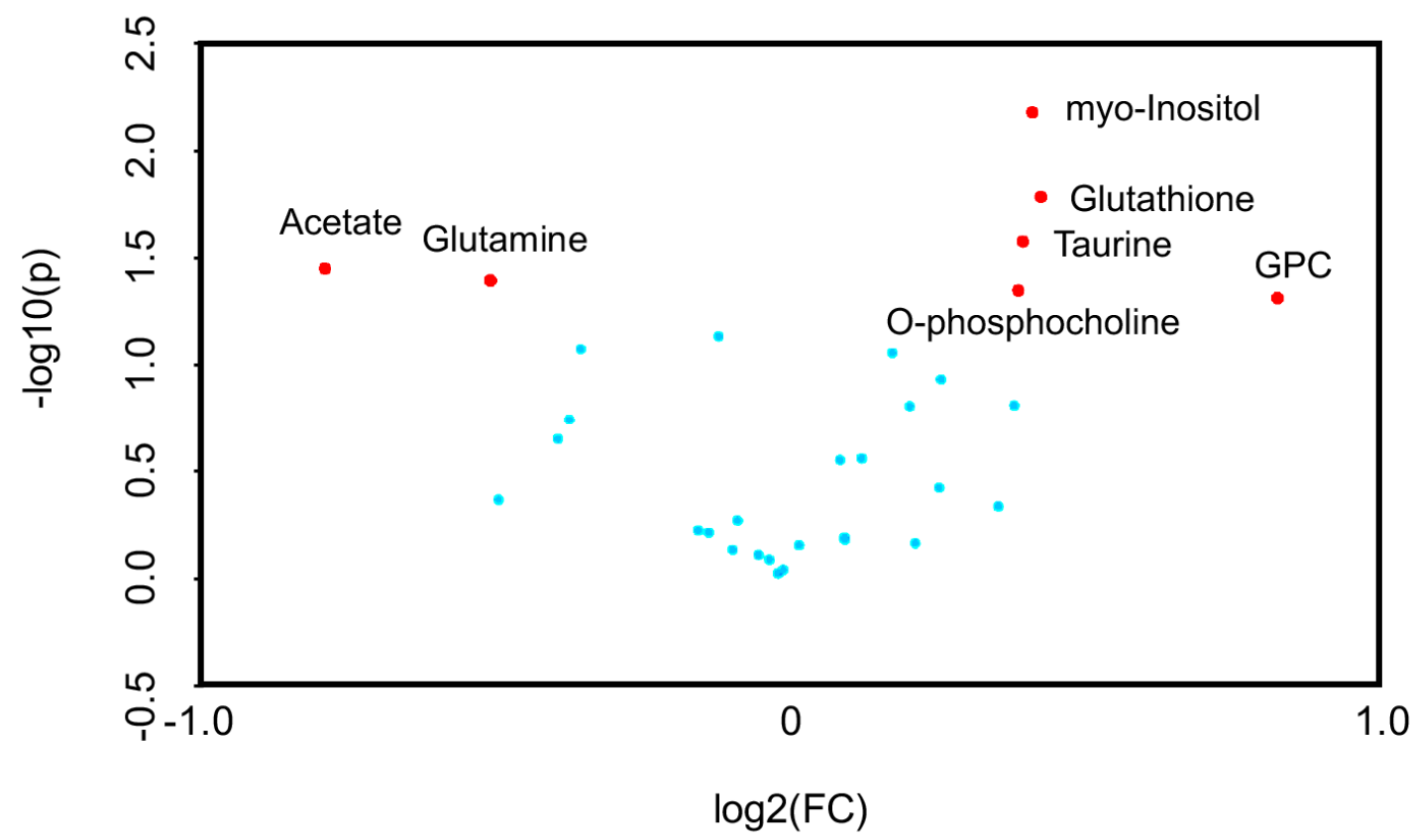

Figure 4. Volcano plots for SpD-induced metabolic changes compared with controls $(n=3)$. Metabolites are considered significant if $\log 2$ (fold change) $>1.2$. The $p$-value threshold was 0.05 . The significantly changed metabolites included acetate, glutamine, myo-inositol, glutathione, taurine, O-phosphocholine, and sn-Glycero-3-phosphocholine (GPC).

Multivariate analysis is used to determine the relative differences in two or more systems that are large and complex. Therefore, as shown in Figure 5A, we performed principal component analysis (PCA) of metabolites from SpD-treated AC16 cells. The aim of PCA is to reduce the dimensionality of original data within the preservation of the variance.

To calculate variable importance in projection (VIP) scores of metabolites, we performed partial least-squares projections for latent structures-discriminant analysis (PLS-DA). Metabolites with VIP scores larger than 1.0 were considered as important (Figure S2). To confirm the "goodness" of the model and the predictive quality, we tested orthogonal partial least-squares projections to latent structures-discriminant analyses (OPLS-DA) on data from SpD-treated AC16 cells and control cells (Figure S3). In PCA, the SpD-treated group and control group revealed class differences showing 95\% confidence regions separating each other. We extended the supervised PLS regression using orthogonal signal correction filters after selecting VIP $>1.0$ metabolites. The metabolites from the SpD-treated AC16 cells significantly differed from the control cell group in the OPLS-DA model. The $R^{2} Y$ model quality parameter was 0.937 , demonstrating that the OPLS-DA model was robust $\left(R^{2} Y\right.$ value near 1.0$)$, and the $Q^{2}$ parameter was 0.597, showing that the model was predictive $\left(Q^{2}>0.5\right)$ (Figure $\left.S 3\right)$. The loading plot of OPLS-DA is shown in Figure 5C. The heat-map analysis of VIP > 1.0 metabolites was represented with logarithmic fold changes (Figure 5B). In comparison with the control group, the most increased and decreased metabolites with SpD treatment were GPC and acetate, respectively. 

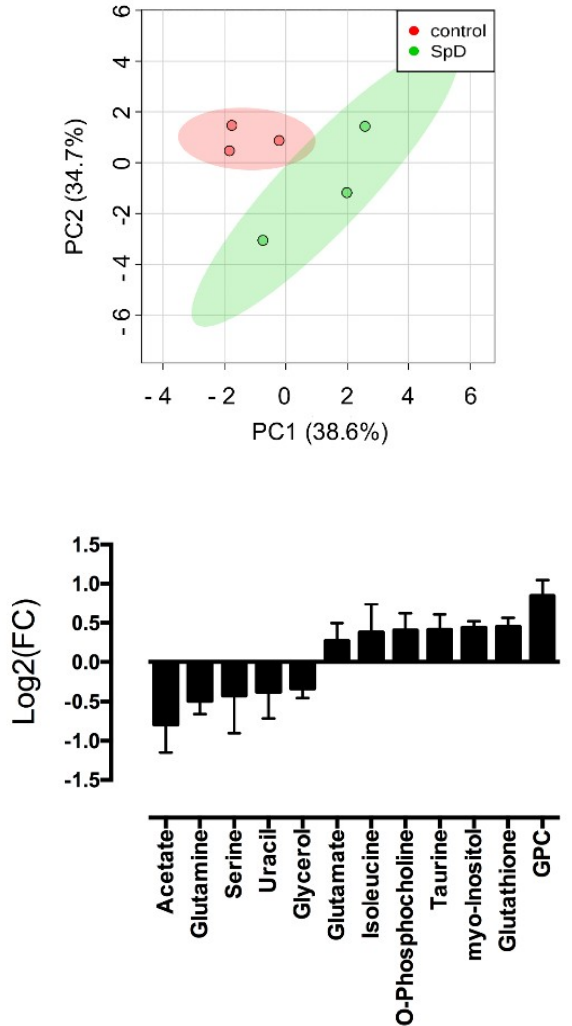

(B)

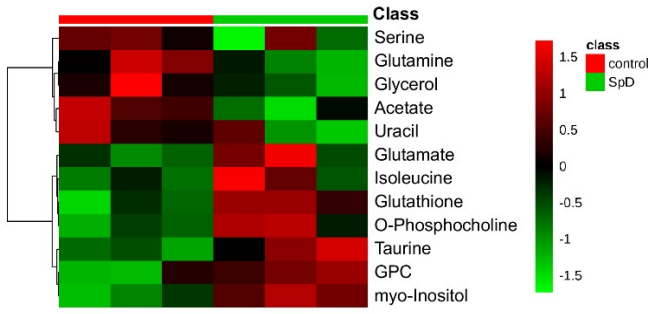

(A)

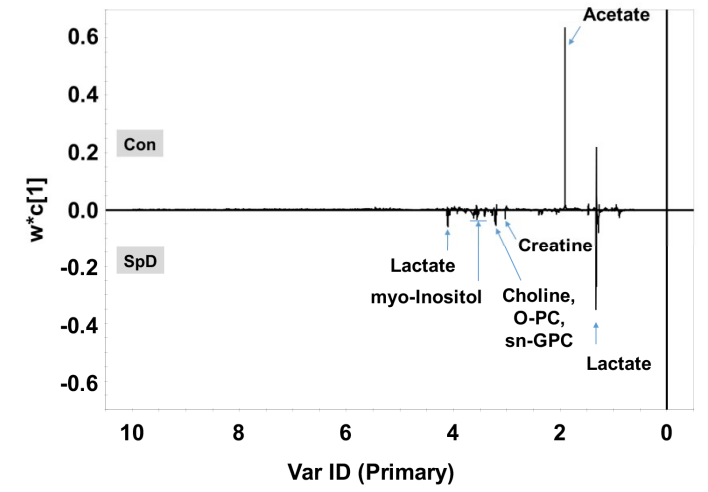

(C)

Figure 5. ${ }^{1} \mathrm{H}-\mathrm{NMR}$ metabolomics for SpD-treated AC16 cells. (A) Principal component analysis (PCA) indicated that metabolites from the SpD-treated $(10 \mu \mathrm{M}, 24 \mathrm{~h})$ group were significantly different from those in the control group; (B) Heat-map analysis of metabolites with variable importance in projection (VIP) score > 1.0. The logarithmic fold changes are shown below. GPC, sn-glycero-3-phosphocholine; (C) The loading plots from orthogonal partial least-squares discriminant analysis (OPLS-DA) for SpD metabolites compared with the control group.

To interpret metabolic changes, correlation networks were generated according to Pearson's correlation coefficients $(|\mathrm{r}|>0.9)$ between metabolites, in a pair-wise fashion. In untreated controls, acetate shared 28 correlations and GPC shared one correlation with other metabolites. Upon SpD treatment, the number of correlations with acetate decreased to eight metabolites, while the number of metabolites correlating with GPC increased to 11 (Figure 6A,B). Pathway enrichment analyses showed that various metabolic processes, including inositol phosphate metabolism, glycerolipid metabolism, and glutathione metabolism, were involved in the SpD treatment effects (Figure 6C and Figure S4). 


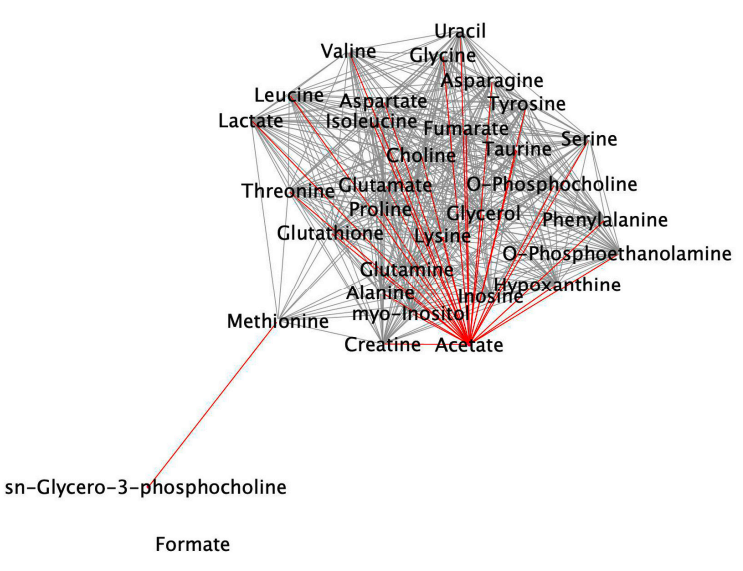

(A)

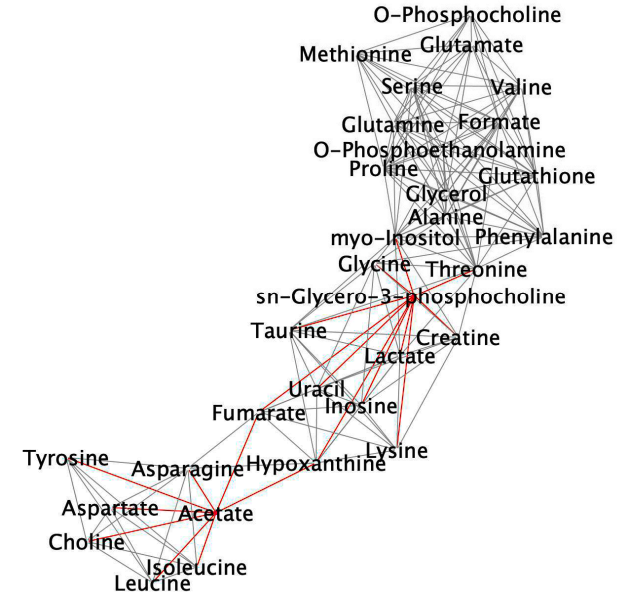

(B)

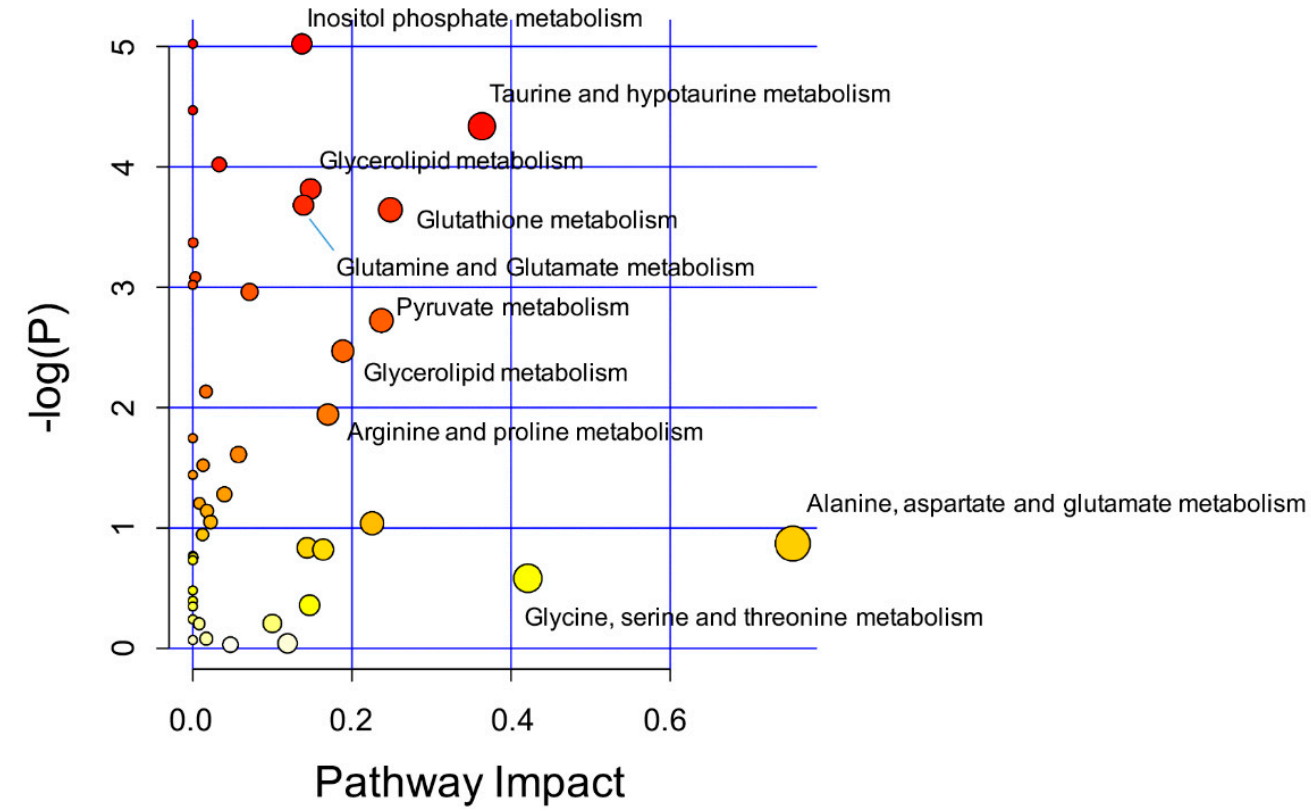

(C)

Figure 6. Network analysis of metabolites altered by SpD $(10 \mu \mathrm{M}, 24 \mathrm{~h})$ treatment of AC16 cells. Networks of metabolites according to their Pearson's correlation coefficients were drawn using Cytoscape program. The networks with significantly increased GPC and decreased acetate are marked as red lines. (A) control and (B) SpD-treated cell metabolites; and, (C) Pathway impact analysis shows the most affected metabolic pathways affected by SpD. Varying colors from yellow to red represent metabolites' significance in the data.

\subsection{Glutathione Metabolism in AC16 Cells Was Significantly Influenced by SpD Treatment}

The integration of the metabolomic and proteomic data was carried out by Integrated Molecular Pathway Level Analysis (IMPaLa) to identify significantly influenced pathways from SpD-treated AC16 cells. The KEGG database showed that VIP > 1.0 metabolites were related to nine over-represented pathways, including glutathione metabolism, protein digestion and absorption, gap junction, and sulfur metabolism (Table 2). The related genes and metabolites are presented in Table S1. The directions of changes in the metabolite-specified proteins are listed in Table 3. 
Table 2. Pathways determined from integration of metabolomic and proteomic data of SpD treated AC16 cells. Identified proteins and metabolites were analyzed using Integrated Molecular Pathway Level Analysis (IMPaLA) for pathway enrichment.

\begin{tabular}{ccccccc}
\hline Pathway & $\begin{array}{c}\text { No. of } \\
\text { Overlapping } \\
\text { Genes }\end{array}$ & $\begin{array}{c}\text { No. of } \\
\text { Genes in } \\
\text { Pathway }\end{array}$ & $\begin{array}{c}\text { No. of } \\
\text { Overlapping } \\
\text { Metabolites }\end{array}$ & $\begin{array}{c}\text { No. of } \\
\text { Metabolites } \\
\text { in Pathway }\end{array}$ & $p$-Value & $\boldsymbol{q}$-Value \\
\hline Glutathione metabolism & 12 & $54(54)$ & 2 & $38(38)$ & $8 \times 10^{-6}$ & $4 \times 10^{-4}$ \\
\hline $\begin{array}{c}\text { Protein digestion and } \\
\text { absorption }\end{array}$ & 12 & $90(90)$ & 3 & $47(47)$ & $3 \times 10^{-5}$ & $9 \times 10^{-4}$ \\
\hline Gap junction & 16 & $88(88)$ & 1 & $11(11)$ & $7 \times 10^{-5}$ & 0.002 \\
\hline Sulfur metabolism & 4 & $10(10)$ & 2 & $33(33)$ & $8 \times 10^{-5}$ & 0.002 \\
\hline Aminoacyl-tRNA biosynthesis & 12 & $66(66)$ & 2 & $52(52)$ & $9 \times 10^{-5}$ & 0.002 \\
\hline Choline metabolism in cancer & 12 & $99(99)$ & 2 & $11(11)$ & $1 \times 10^{-4}$ & 0.002 \\
\hline $\begin{array}{c}\text { Central carbon metabolism } \\
\text { in cancer }\end{array}$ & 11 & $65(65)$ & 2 & $37(37)$ & $1 \times 10^{-4}$ & 0.003 \\
\hline Long-term depression & 9 & $60(60)$ & 1 & $9(9)$ & 0.003 & 0.033 \\
\hline Long-term potentiation & 9 & $67(67)$ & 1 & $7(7)$ & 0.004 & 0.043 \\
\hline
\end{tabular}

Table 3. Direction of $\log$ (FC) of metabolite-specified genes/proteins in SpD/Dox treated AC16.

\begin{tabular}{|c|c|c|c|c|c|}
\hline \multirow{2}{*}{ Pathway } & \multirow{2}{*}{ Gene } & \multicolumn{3}{|c|}{ Direction of $\log (\mathrm{FC})$ vs. Control } & \multirow{2}{*}{ Protein } \\
\hline & & SpD & Dox & Dox and $\mathrm{SpD}$ & \\
\hline $\begin{array}{l}\text { Glutathione } \\
\text { metabolism }\end{array}$ & TXNDC12 & DOWN & DOWN & UP & Thioredoxin domain-containing protein 12 \\
\hline \multirow[t]{2}{*}{$\begin{array}{l}\text { Protein digestion } \\
\text { and absorption }\end{array}$} & COL4A1 & DOWN & DOWN & UP & Collagen alpha-1(IV) chain \\
\hline & COL5A2 & DOWN & DOWN & UP & Collagen alpha-2(V) chain \\
\hline \multirow[t]{2}{*}{ Gap junction } & MAPK3 & DOWN & $\mathrm{UP}$ & DOWN & Mitogen-activated protein kinase \\
\hline & MAP2K1 & UP & DOWN & UP & $\begin{array}{l}\text { Dual specificity mitogen-activated protein } \\
\text { kinase kinase } 1\end{array}$ \\
\hline Sulfur metabolism & BPNT1 & DOWN & DOWN & UP & $3^{\prime}\left(2^{\prime}\right), 5^{\prime}$-bisphosphate nucleotidase 1 \\
\hline \multirow[t]{2}{*}{$\begin{array}{l}\text { Aminoacyl-tRNA } \\
\text { biosynthesis }\end{array}$} & FARSB & DOWN & DOWN & UP & Phenylalanine-tRNA ligase beta subunit \\
\hline & TARS & UP & UP & DOWN & Threonine-tRNA ligase, cytoplasmic \\
\hline \multirow[t]{5}{*}{$\begin{array}{l}\text { Choline metabolism } \\
\text { in cancer }\end{array}$} & MAP2K1 & UP & DOWN & UP & $\begin{array}{l}\text { Dual specificity mitogen-activated protein } \\
\text { kinase kinase } 1\end{array}$ \\
\hline & AKT2 & DOWN & UP & UP & RAC-beta serine/threonine-protein kinase \\
\hline & RAC1 & DOWN & DOWN & UP & $\begin{array}{l}\text { Isoform B of Ras-related C } 3 \text { botulinum } \\
\text { toxin substrate } 1\end{array}$ \\
\hline & RHEB & DOWN & UP & UP & GTP-binding protein Rheb \\
\hline & MAPK3 & DOWN & UP & DOWN & Mitogen-activated protein kinase \\
\hline \multirow[t]{5}{*}{$\begin{array}{c}\text { Central carbon } \\
\text { metabolism in cancer }\end{array}$} & MAP2K1 & UP & DOWN & UP & $\begin{array}{l}\text { Dual specificity mitogen-activated protein } \\
\text { kinase kinase } 1\end{array}$ \\
\hline & PDHB & UP & DOWN & DOWN & $\begin{array}{l}\text { Isoform } 2 \text { of Pyruvate dehydrogenase E1 } \\
\text { component subunit beta, mitochondrial }\end{array}$ \\
\hline & MTOR & UP & DOWN & UP & Serine/threonine-protein kinase mTOR \\
\hline & AKT2 & DOWN & UP & UP & RAC-beta serine/threonine-protein kinase \\
\hline & MAPK3 & DOWN & UP & DOWN & Mitogen-activated protein kinase \\
\hline \multirow[t]{2}{*}{$\begin{array}{l}\text { Long-term } \\
\text { depression }\end{array}$} & MAP2K1 & UP & DOWN & UP & $\begin{array}{l}\text { Dual specificity mitogen-activated protein } \\
\text { kinase kinase } 1\end{array}$ \\
\hline & MAPK3 & DOWN & UP & DOWN & Mitogen-activated protein kinase \\
\hline \multirow[t]{2}{*}{$\begin{array}{l}\text { Long-term } \\
\text { potentiation }\end{array}$} & MAP2K1 & UP & DOWN & UP & $\begin{array}{l}\text { Dual specificity mitogen-activated protein } \\
\text { kinase kinase } 1\end{array}$ \\
\hline & CAMK2D & DOWN & UP & UP & \\
\hline
\end{tabular}




\subsection{SpD Functioned as an Antioxidant in AC16 Cells}

To test the antioxidant ability of SpD, oxidative stress was induced in AC16 cells using $\mathrm{H}_{2} \mathrm{O}_{2}$ or cobalt chloride with high glucose for $24 \mathrm{~h}$. The DCF-DA fluorescence showed that SpD treatment reduced ROS in AC16 cells (Figure 7).

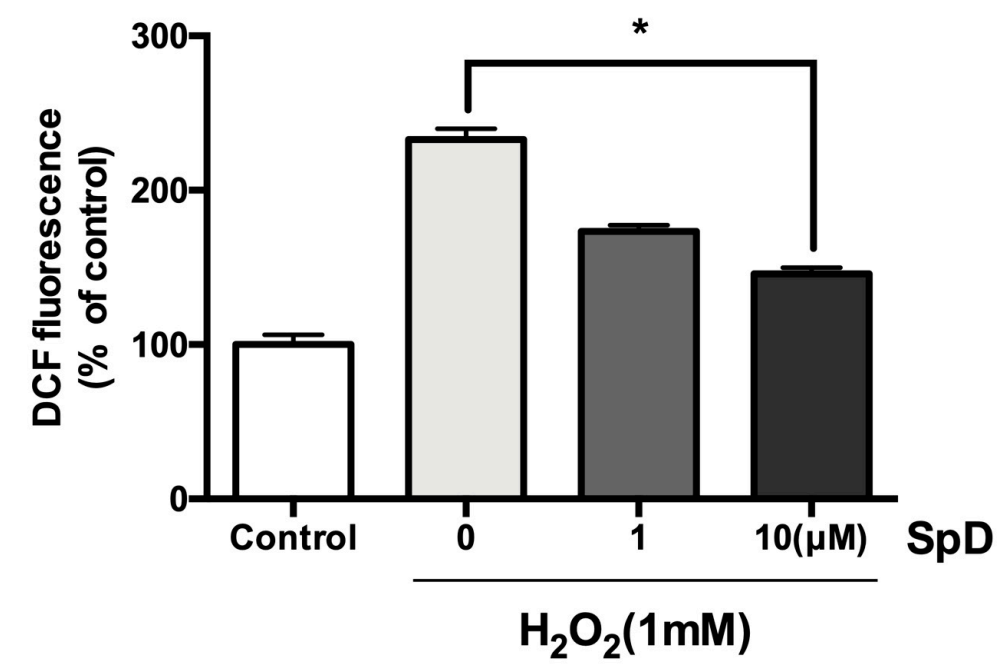

(A)

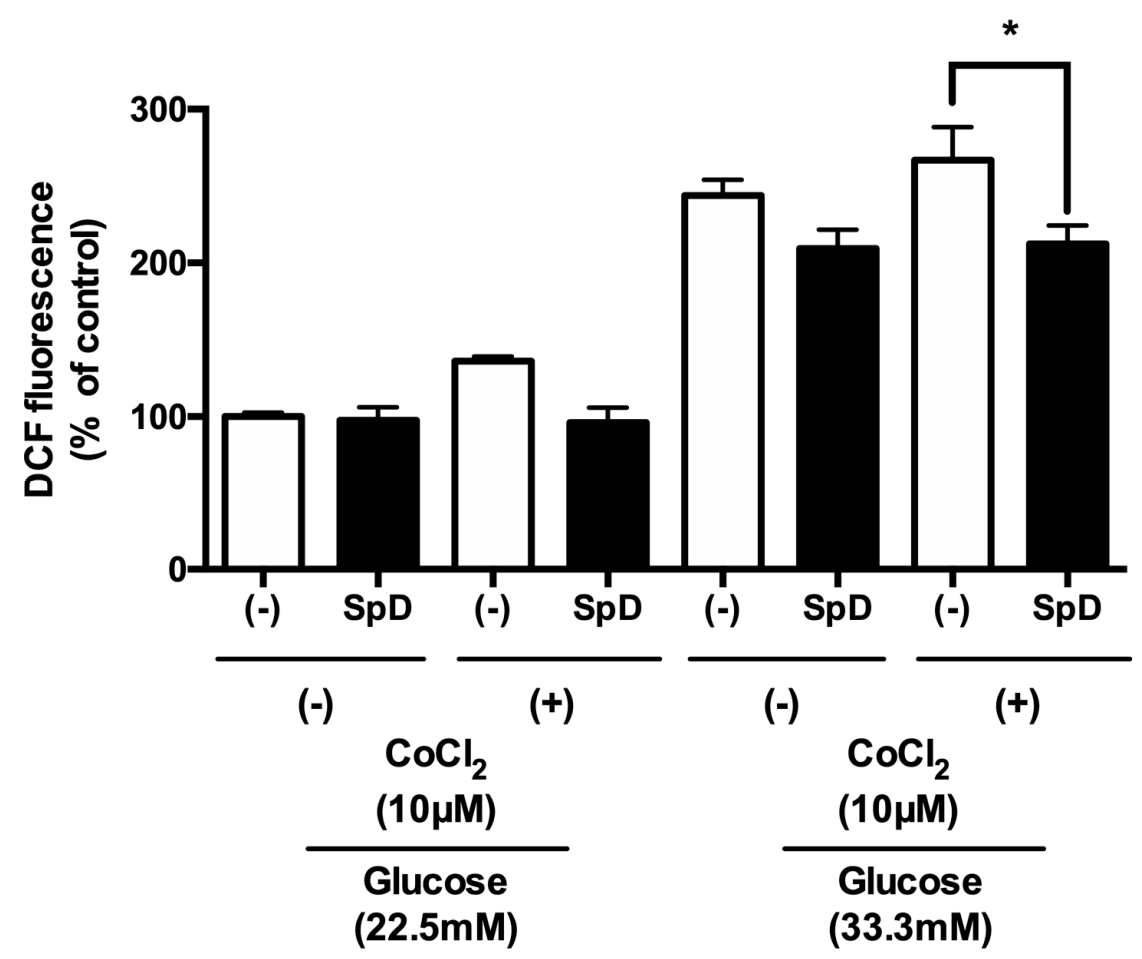

(B)

Figure 7. SpD showed antioxidant activity in AC16 cells treated with $\mathrm{H}_{2} \mathrm{O}_{2}$ or cobalt chloride and hyperglycemic stress. (A) Reactive oxygen species generation was induced in AC16 cells using $1 \mathrm{mM}$ $\mathrm{H}_{2} \mathrm{O}_{2}$ and $\mathrm{SpD}(0-10 \mu \mathrm{M})$ was co-treated for $24 \mathrm{~h}$. ${ }^{*} p<0.05$ compared with $1 \mathrm{mM} \mathrm{H}_{2} \mathrm{O}_{2}$ group without $\mathrm{SpD}$; (B) Cobalt chloride (a hypoxia-mimetic agent) and hyperglycemia ( $33.3 \mathrm{mM}$ glucose in media) were applied to AC16 cells. The cells were incubated with ', $7^{\prime}$-dichlorofluorescein diacetate (DCF-DA) $(20 \mu \mathrm{M})$ for $20 \mathrm{~min}$ at $37^{\circ} \mathrm{C}$ and the intensity of fluorescence was measured at $485 \mathrm{~nm} .{ }^{*} p<0.05$ compared with no SpD treated group. 


\subsection{SpD Increased Mitochondrial ATP Production and Oxygen Consumption}

$\mathrm{SpD}$ treatment increased intracellular ATP production and the oxygen consumption rate (OCR) in AC16 cells (Figure 8A,B). In addition, SpD treatment increased ATP production in $\mathrm{H}_{2} \mathrm{O}_{2}$-treated cells (Figure $8 \mathrm{C}$ ). Co-treatment with doxorubicin $(0.1 \mu \mathrm{M})$ and $\mathrm{SpD}$ for $24 \mathrm{~h}$ increased ATP production as compared to doxorubicin treatment alone (Figure 8D). In our study, SpD showed enhanced antioxidant capacity when compared with equimolar echinochrome A (Figure S6).

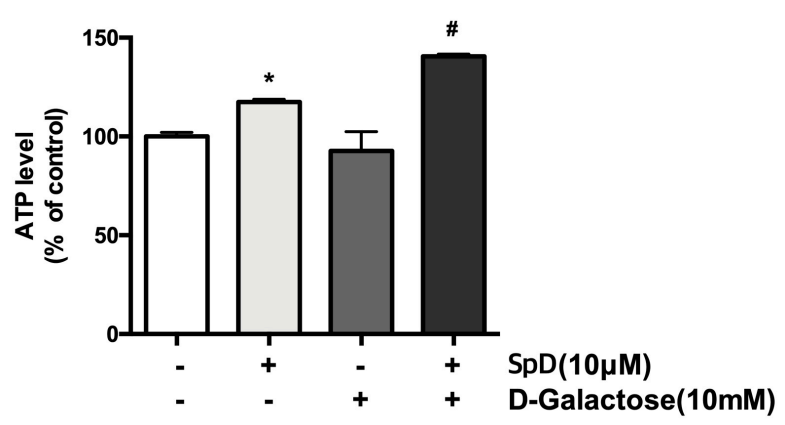

(A)

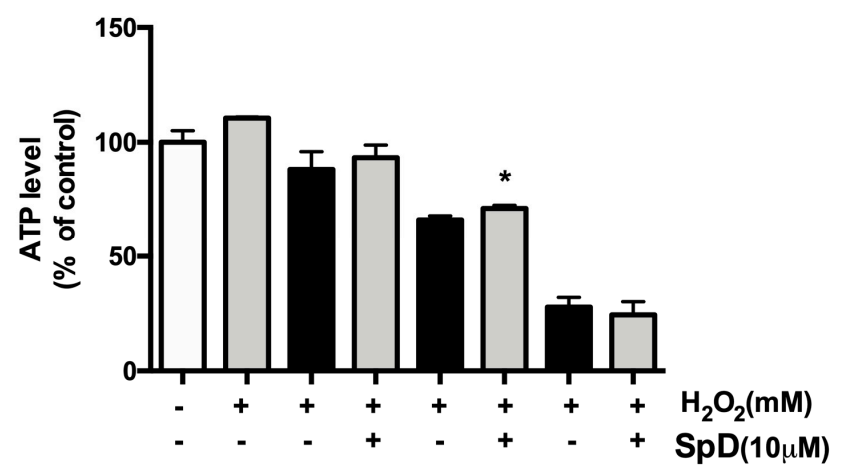

(C)

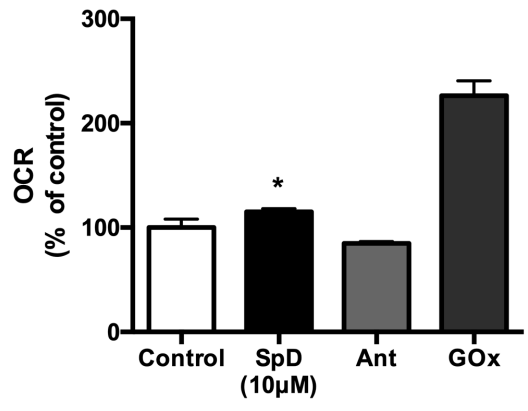

(B)

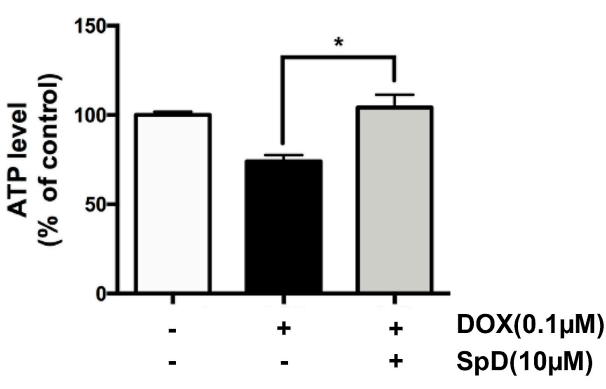

(D)

Figure 8. SpD caused increased ATP production and oxygen consumption rate (OCR) in AC16 cells. (A) SpD $(10 \mu \mathrm{M})$ increased ATP production in AC16 cells. D-galactose $(10 \mathrm{mM})$ was added to reduce cytosolic glycolytic ATP production. By changing energy metabolism in cardiomyocytes by replacing glucose with galactose, high concentrations of galactose could prevent ATP production except that of mitochondria by oxidative phosphorylation (OXPHOS); (B) SpD $(10 \mu \mathrm{M})$ increased OCR. Antimycin A (Ant, $1 \mu \mathrm{M}$, a Complex III inhibitor) was used as a cell-based negative control and glucose oxidase (GOx, $1 \mathrm{mg} / \mathrm{mL}$ ) was used as a cell-free positive control. (C) SpD increased ATP levels under $\mathrm{H}_{2} \mathrm{O}_{2}$ induced oxidative stress. (D) SpD increased ATP production in the presence of doxorubicin $(0.1 \mu \mathrm{M})$. * $p<0.05$ compared with untreated controls, $\# p<0.05$ compared with the D-galactose-treated group.

\subsection{SpD Protected against Doxorubicin-Induced Mitochondrial Damage in AC16 Cells}

Using tetramethylrhodamine (TMRE) and rhodamine-2 (rhod-2) staining, we compared mitochondrial membrane potential and mitochondrial $\mathrm{Ca}^{2+}$ in doxorubicin and SpD-treated AC16 cells (Figure 9). Doxorubicin treatment for $24 \mathrm{~h}$ decreased the TMRE intensity of AC16 cells in a dose-dependent manner. The doxorubicin-treated cells also showed increased cytosolic diffusion of rhod-2. We treated AC16 cells with $10 \mu \mathrm{M}$ of SpD in the presence of $0.1-1.0 \mu \mathrm{M}$ doxorubicin. SpD treatment attenuated the loss of mitochondrial membrane potential that is induced by doxorubicin (Figure 9A,B). SpD treatment reduced the cytosolic overload of mitochondrial $\mathrm{Ca}^{2+}$ in doxorubicin-treated cells (Figure 9C,D). 

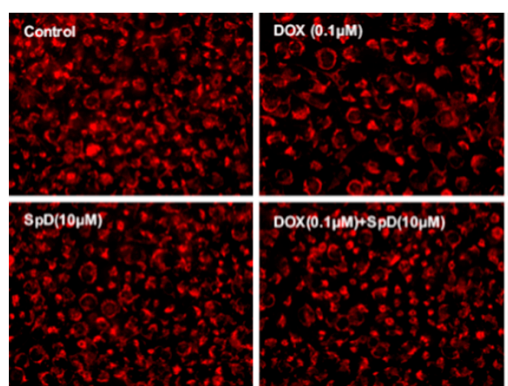

(A)
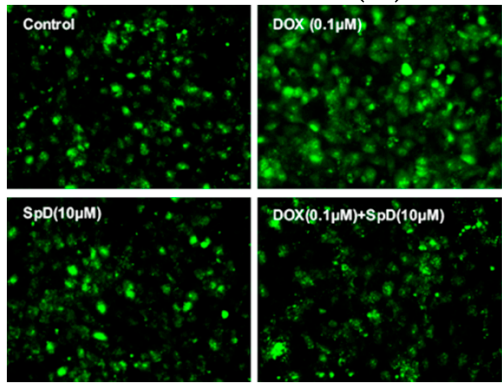

(C)
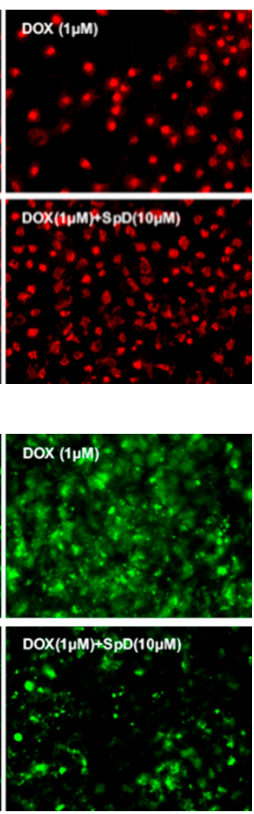

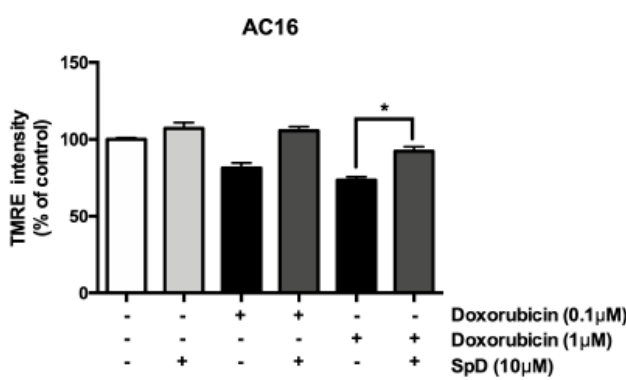

(B)

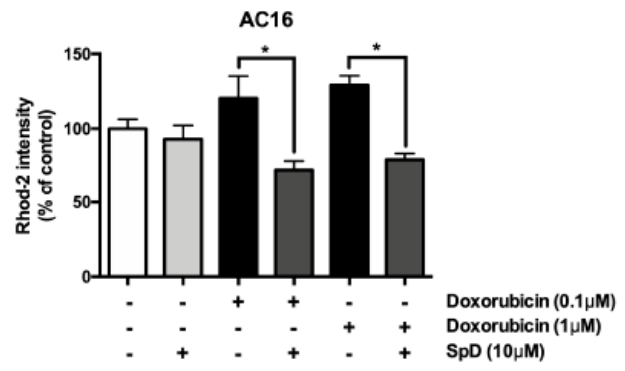

(D)

Figure 9. SpD attenuated doxorubicin-induced mitochondrial membrane potential and mitochondrial calcium changes in AC16 cells. (A) Mitochondrial membrane potential $\left(\Delta \psi_{\mathrm{m}}\right)$ in AC16 cells was indicated by TMRE fluorescence. The cells were treated with doxorubicin (0.1-1.0 $\mu \mathrm{M})$ with/without SpD $(10 \mu \mathrm{M})$; (B) The intensity of tetramethylrhodamine (TMRE) staining was measured using fluorometry at $550_{\mathrm{Ex}} / 590_{\mathrm{Em}} \mathrm{nm}$. Doxorubicin decreased mitochondrial membrane potential in a dose-dependent manner. Co-treatment with $\mathrm{SpD}$ attenuated the membrane potential loss; (C) Mitochondrial calcium was localized using rhod-2, a selective indicator for mitochondrial $\mathrm{Ca}^{2+}$; and, (D) The intensity of rhod-2 was measured at $552_{\mathrm{Ex}} / 581_{\mathrm{Em}} \mathrm{nm}$. Doxorubicin induced diffusion of mitochondrial $\mathrm{Ca}^{2+}$ to the cytosolic space but $\mathrm{SpD}$ co-treatment attenuated the $\mathrm{Ca}^{2+}$ diffusion. ${ }^{*} p<0.05$ compared with the doxorubicin-treated group.

\subsection{SpD Did Not Interfere with the Anticancer Effects of Doxorubicin in MCF-7 Cells}

$\mathrm{SpD}$ did not inhibit the cytotoxic activity of doxorubicin in MCF-7 cells (Figure 10). Human breast cancer MCF-7 cells and human cervical cancer HeLa cells showed reduced cell viability after treatment with SpD above $100 \mu \mathrm{M}$ (Figure 10A and Figure S7A). When the SpD/doxorubicin co-treated cells were compared with the cells that were treated with doxorubicin alone, there were no significant differences in ROS level (Figure 10B), loss of mitochondrial membrane potential (Figure 10C,D), or $\mathrm{Ca}^{2+}$ overload (Figure 10E,F). Similar experiments using the HeLa human cervical cancer cell line showed the same lack of inhibition of cytotoxicity (Figure S7). Interestingly, SpD treatment inhibited cell migration in a wound healing test (Figure S8). 


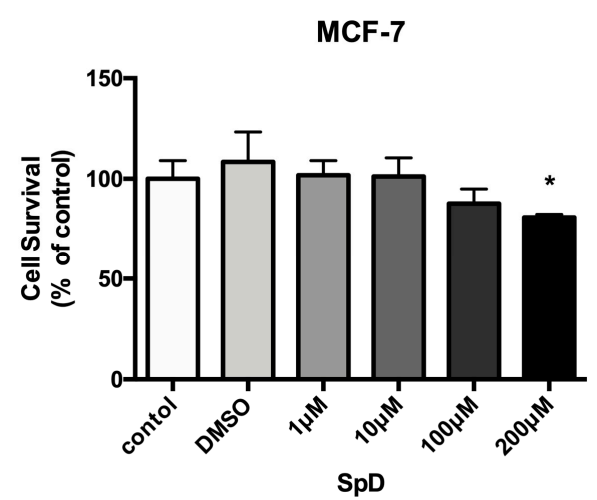

(A)
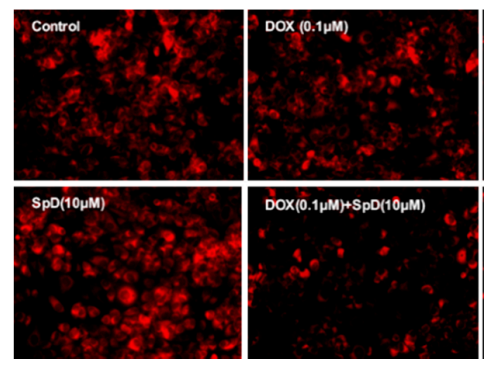

(C)
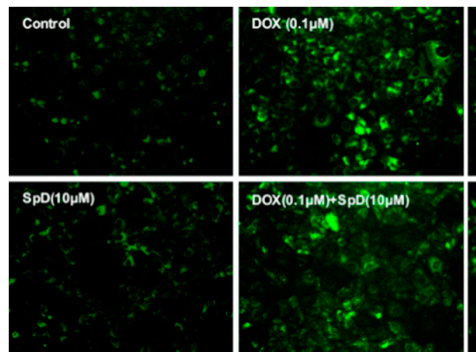

(E)

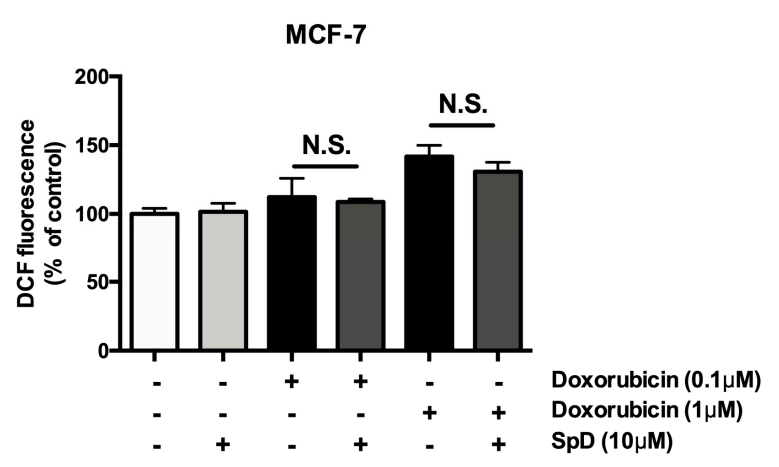

(B)

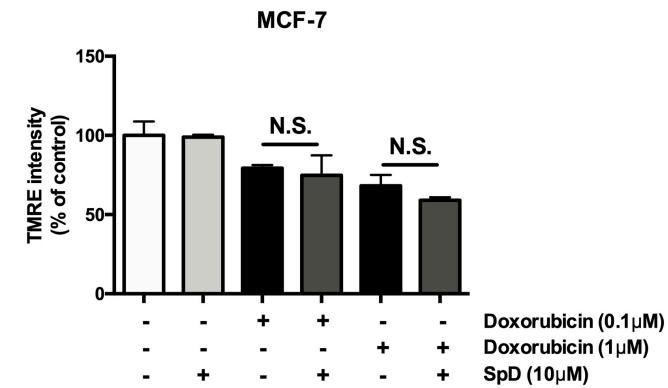

(D)

MCF-7

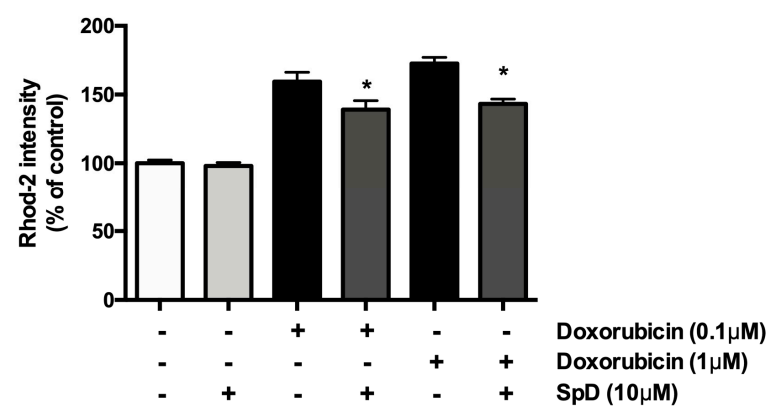

(F)

Figure 10. SpD did not inhibit the cytotoxicity of doxorubicin. (A) SpD induced MCF-7 cell death at 100-200 $\mu \mathrm{M}$. ${ }^{*} p<0.05$ compared with the untreated control; (B) The co-treatment of $\mathrm{SpD}$ and doxorubicin showed similar levels of ROS compared with the doxorubicin alone group; (C) Mitochondrial membrane potential was visualized using TMRE staining in $\mathrm{SpD} /$ doxorubicin-treated MCF-7 cells; (D) The TMRE intensity measured by fluorometry is shown; (E) Mitochondrial $\mathrm{Ca}^{2+}$ level is indicated using rhod-2 dye in SpD/doxorubicin-treated MCF-7 cells; (F) The rhod-2 intensity was measured by fluorometry. ${ }^{*} p<0.05$ compared with doxorubicin treated groups without $\mathrm{SpD}$. $\mathrm{ROS}=$ reactive oxygen species.

\section{Discussion}

There have been many efforts to overcome the cardiotoxicity of doxorubicin in cancer treatment. The $\mathrm{IC}_{50}$ (drug concentration required to inhibit cell growth by $50 \%$ ) of doxorubicin for breast cancer cell lines has been reported to be between $1-4 \mu \mathrm{M}$ after $24 \mathrm{~h}$ treatment $\left(\mathrm{IC}_{50}=1 \mu \mathrm{M}\right.$ for MCF-10F; $4 \mu \mathrm{M}$ for MCF-7; and, $1 \mu \mathrm{M}$ for MDA-MB-231 cells) [19]. We used $10 \mu \mathrm{M}$ of SpD, which induced no significant viability changes in either cardiomyocytes or cancer cells. From animal models using Histochrome $^{\circledR}$ (echinochrome A), 1-10 mg/ $\mathrm{kg}$ of doses have been reported to act as antioxidant in cardiomyocytes, which approximately correspond to 3-30 $\mu \mathrm{M}$ [20]. In our study, echinochrome A and $\mathrm{SpD}$ showed cardioprotective activity when treated with $0.1 \mu \mathrm{M}$ doxorubicin. In equimolar treatment, 
SpD showed better antioxidant activity and ATP production than echinochrome A. It might be reasonable to assume that cell viability decreases with increased doxorubicin incubation time. However, lower concentrations $(<0.25 \mu \mathrm{M})$ of doxorubicin often show a low dose-time response relationship in cancer cells [21]. Cardiomyocytes and cancer cells have different mechanisms of doxorubicin-induced apoptosis. In cardiomyocytes, doxorubicin induces apoptosis by a $\mathrm{H}_{2} \mathrm{O}_{2}$-mediated mechanism, which is largely independent of p53 activation. In contrast, the p53 tumor suppressor plays an important role in doxorubicin-induced apoptosis in cancer cells [22-24].

Univariate analyses, such as fold change comparison, $t$-test, and volcano plot suggest overall shapes of measured data and multivariate analyses, including PCA, PLS-DA, and OPLS-DA, often reveal the latent structure of the data. When quantitatively analyzing multi-parametric metabolite responses, it is critical to specify all of the independent and dependent variables to be included [25]. In biological systems, metabolites are the end product of enzymatic and other protein activity, and therefore they are not independent from biological interactions. In our study, correlation network analysis and pathway enrichment analysis of VIP > 1.0 metabolites (e.g., GPC, acetate) showed that glycerolipid metabolism, glutathione metabolism, and pyruvate metabolism were significantly affected by SpD treatment in cardiomyocyte [26]. In addition to production during ethanol metabolism, acetate is transported into cells by proteins of the monocarboxylate transporter family or it is generated intracellularly by protein deacetylases and acetyl-CoA hydrolases $[27,28]$. In the cytosol, CoA is acetylated by acetyl-CoA synthetase to produce acetyl-CoA. In contrast, in mitochondria, acetyl-CoA is produced through the pyruvate dehydrogenase complex reactions. Acetyl-CoA participates in the citric acid cycle and $\beta$-oxidation of fatty acids to produce cellular energy (e.g., ATP). In addition to increased acetate consumption, SpD might increase cytosolic glycolysis and entrance of glutamate into the citric acid cycle, which could be shown by an increased lactate concentration and increased ratio of glutamate to glutamine (from 20.9 to 35.3; calculated as shown in Table 1). SpD treatment increased the accumulation of cytosolic osmolytes such as GPC, myo-inositol, and free amino acids (e.g., taurine and glycine), which are critical for the viability of cells. The integrated analysis with mass spectrometry based proteomics indicated that the glutathione metabolism of AC16 cells was most affected by SpD treatment. Since we measured the reduced form of glutathione (GSH) using Chenomx NMR Suit 7.1, the increased concentration of glutathione represents the increase of GSH reduced glutathione/GSSG oxidized glutathione ratio. Using the luciferase mediated method, we confirmed the increase of GSH/GSSG ratio in a dose-dependent manner (Figure S9).

Based on the acquired results, we hypothesized that SpD mainly exerted its function as antioxidant in the process of protection of cardiomyocytes against the cytotoxicity of doxorubicin. Since the cytotoxicity of doxorubicin on cardiomyocytes is known to be based on ROS increase, we tested SpD activity in ROS generating environments. We tested $1 \mathrm{mM} \mathrm{H}_{2} \mathrm{O}_{2}$ concentration, which might be increased by constitutively active NADPH oxidase 4 (NOX4) [29]. In addition, we assessed the antioxidant ability of SpD in cobalt chloride and hyperglycemic condition. The hypoxia mimetic cobalt chloride and hyperglycemic concentrations of glucose $(33.3 \mathrm{mM})$ are known to increase intracellular ROS [30-34]. Hyperglycemia induces hypoxia-induced cell death via the influx of calcium in diabetic cardiomyopathy [35-37]. Oxidative stress might cause cardiac mitochondrial dysfunction, leading to cell death $[38,39]$.

Since the integrated analysis that is located the mitochondrial proteins clustered together at $\mathrm{SpD}$ treatment, we had to focus the mitochondrial ATP production by SpD treatment. To differentiate ATP production from the cytosol versus mitochondria, we added D-galactose $(10 \mathrm{mM})$ to the culture media. By competing with glucose in the cytosol, D-galactose reduces cytosolic glycolysis, resulting in decreased cytosolic ATP production. Galactokinase produces galactose 1-phosphate from galactose, utilizing ATP. Uridine diphosphate (UDP)-galactose 4-epimerase converts UDP-glucose and galactose 1-phosphate into UDP-galactose and glucose 1-phosphate, respectively. Galactose participates in glycolysis by consuming ATP and reducing cytosolic glycolysis rates [40-42]. SpD treatment increased 
ATP production, even in $10 \mathrm{mM}$ galactose media, which suggested the enhancement of mitochondrial ATP production with increased OCR.

In cardiomyocytes, doxorubicin has been known to induce oxidized state in mitochondrial redox potential to trigger mitochondrial depolarization and elevated calcium levels, which suppresses ATP production via oxidative phosphorylation.

As the mitochondrial dysfunction occurs, the cells are subjected to ATP depletion and become more dependent on ADP metabolism to compensate the ATP/ADP ratio [43]. In our study, the SpD treatment did not inhibit the anticancer activity of doxorubicin while protecting cardiomyocytes at identical concentration via increasing ATP production. Our approaches might provide some clues for the potential cardioprotective mechanisms of SpD in a combination therapy with doxorubicin. Nevertheless, further studies are still needed for evaluation of the drug.

\section{Materials and Methods}

\subsection{Cell Culture and Treatment}

Human cardiomyocyte cell line AC16 were purchased from Merch Company (SCC 109). Rat cardiomyocyte cell line H9c2 (CRL-1466), human breast cancer cell line MCF-7 (HTB-22), and human cervical cancer cell line HeLa (CCL-2) were purchased from America Tissue Type Collection (ATCC, Bethesda, Rockville, MD, USA). Cells were routinely cultured in Dulbecco's modified Eagle's medium (DMEM) containing $25 \mathrm{mmol} / \mathrm{L}$ glucose and L-glutamine (Sigma, St. Louis, MO, USA) and 10\% fetal bovine serum (FBS) (HyClone, Logan, UT, USA). Cells were maintained at $37{ }^{\circ} \mathrm{C}$ and $5 \% \mathrm{CO}_{2}$. For $10 \mathrm{mM}$ galactose DMEM, D-galactose (Sigma, St. Louis, MO, USA) was added to the media. Spinochrome D (SpD, purity 98\%) was isolated from the sea urchin Scaphechinus mirabilis, as described in [44], as the red powder with m.p. $>320^{\circ} \mathrm{C}$ and spectral characteristics, as in [45].

\subsubsection{Cell Viability Assay}

Cells were seeded in 96-well plates at $2 \times 10^{4}$ cells/well until adherent. Cells were treated with SpD for $24 \mathrm{~h}$ and then $10 \mu \mathrm{L}$ of Cell Counting Kit-8 reagent (CCK-8, Dojindo Molecular Technologies, Kyushu, Japan) was added into each well for 20-30 min at $37^{\circ} \mathrm{C}$. The absorbance was read using a SpectraMax microplate reader (Molecular Devices, San Jose, CA, USA) at $450 \mathrm{~nm}$.

\subsubsection{Intracellular ATP Measurement}

The ATP levels that are produced by cardiomyocytes were measured by the Luciferin-Luciferase reaction, according to the manufacturer's instructions (Cayman Chemicals, Ann Arbor, MI, USA). Cells were plated at $2 \times 10^{4}$ cells/well in 96-well plates and incubated with test compounds at $37^{\circ} \mathrm{C}$ and $5 \% \mathrm{CO}_{2}$ for $24 \mathrm{~h}$. Cells were lysed using $50 \mu \mathrm{L}$ of lysis buffer (Triton X100; $0.1 \%$ ), mixed with $50 \mu \mathrm{L}$ of ATP measurement solution containing Luciferin-Luciferase, and then incubated at room temperature for 10-15 min. The luminescence was read using a luminometer (SpectraMax M2e; Molecular Devices, Sunnyvale, CA, USA) and expressed as relative light units. The ATP levels of the control and drug-treated samples were compared to ensure that the reading was exclusive to the ATP produced by drug-treated cardiomyocytes.

\subsubsection{Oxygen Consumption Ratio (OCR) Measurement}

The OCR in cardiomyocytes was measured using a MitoXpress ${ }^{\circledR}$ probe (Cayman Chemicals, Ann Arbor, MI, USA) according to the manufacturer's instructions. Cells were plated at $2 \times 10^{4}$ cells/well in 96-well plates and incubated with SpD at $37^{\circ} \mathrm{C}$ and $5 \% \mathrm{CO}_{2}$ for $24 \mathrm{~h}$. After replacing the spent media with $160 \mu \mathrm{L}$ of $10 \%$ FBS-DMEM containing SpD, $10 \mu \mathrm{L}$ of MitoXpress ${ }^{\circledR}$ Xtra Solution, and $100 \mu \mathrm{L}$ of mineral oil were added to all wells. The plates were incubated at $37^{\circ} \mathrm{C}$ and $5 \% \mathrm{CO}_{2}$ for 10-20 min and then the fluorescence was read at $380 \mathrm{~nm}$ excitation $/ 650 \mathrm{~nm}$ emission on a fluorometer with a delay time of $100 \mu$ s (SpectraMax M2e). 


\subsubsection{Intracellular ROS Levels}

The ROS levels were measured using $2^{\prime}, 7^{\prime}$-dichlorofluorescein diacetate (DCF-DA) (Sigma-Aldrich). Cells were plated at $2 \times 10^{4}$ cells/well in 96-well plates and incubated with test compounds at $37^{\circ} \mathrm{C}$ and $5 \% \mathrm{CO}_{2}$ for $24 \mathrm{~h}$. Subsequently, the cells were washed three times with phosphate-buffered saline (PBS) and incubated in the dark with $20 \mu \mathrm{M}$ DCF-DA for $30 \mathrm{~min}$ at $37^{\circ} \mathrm{C}$. The cells were washed twice with PBS. The fluorescence was measured using a fluorometer at $485 \mathrm{~nm}$ excitation/535 $\mathrm{nm}$ emission.

\subsubsection{Measurement of Mitochondrial Membrane Potential}

Mitochondrial membrane potential was measured using tetramethylrhodamine (TMRE; Thermo Fisher Scientific, Scotts Valley, CA, USA). Cells were incubated with $200 \mathrm{nM}$ TMRE in the dark for $30 \mathrm{~min}$ at $37{ }^{\circ} \mathrm{C}$ and $5 \% \mathrm{CO}_{2}$. After washing, the fluorescence was measured at $550 \mathrm{~nm}$ excitation/590 nm emission and cells were imaged using a fluorescence microscope (Olympus, IX71; Olympus, Tokyo, Japan).

\subsubsection{Measurement of Mitochondrial Calcium}

Mitochondrial calcium was measured using rhod-2/AM (TMRE; Thermo Fisher Scientific). Cells were incubated with $1 \mu \mathrm{M}$ rhod-2 for $30 \mathrm{~min}$. After PBS washing, the fluorescence was measured at $552 \mathrm{~nm}$ excitation/581 $\mathrm{nm}$ emission and cells were imaged using a fluorescence microscope.

\subsubsection{Cell Migration Assay}

Scratch wound assays were used for cancer cell mobility analyses. MCF-7 and HeLa cells were seeded into 25 -well cell culture plates at a concentration of $2 \times 10^{4}$ cells and were maintained in $10 \%$ FBS-DMEM until $70-80 \%$ confluent. The scratch was carefully made using a 20P sterile pipette tip. The remaining cellular debris was gently removed with PBS. The wounded monolayer was incubated in $10 \%$ FBS-DMEM containing $10 \mu \mathrm{M}$ SpD for $24 \mathrm{~h}$. The cell migration was observed under $4 \times$ by using a phase contrast microscope.

\subsection{LC-MS/MS Analysis and Database Searching}

The trypsinized peptides from $50 \mu \mathrm{g}$ of SpD-treated cell supernatant were analyzed using an LTQ-Orbitrap Velos ${ }^{\mathrm{TM}}$ mass spectrometer coupled with an EASY-nLC II (Thermo Fisher Scientific, Waltham, MA, USA). The Uniprot human database was used for peptide searching. The protein identification was confirmed if the normalized fold change (FC) was higher than 1.30 (upregulated) or less than 0.77 (downregulated). The confidence level (CI) was $95 \%$ based on pair-wise analyses as compared with untreated controls. Relative peptide abundance was quantified with Scaffold using the Top 3 total ion chromatogram method. The differentially expressed proteins were categorized into Gene Ontology terms, i.e., biological process, cellular component, and molecular function.

\section{3. ${ }^{1} \mathrm{H}-\mathrm{NMR}$ Metabolomics}

The high-resolution magic-angle spinning nuclear magnetic resonance (HR-MAS NMR) spectra were recorded using an Agilent $600 \mathrm{MHz}$ spectrometer that was equipped with a $4 \mathrm{~mm} \mathrm{gHX}$ NanoProbe (Agilent Technologies, Santa Clara, CA, USA). All spectra were acquired at $600.167 \mathrm{MHz}$. The acquisition time was $1.703 \mathrm{~s}$, relaxation delay was $1 \mathrm{~s}$, and a total of 128 scans was obtained. The Carr-Purcell-Meiboom-Gill (CPMG) pulse sequence was used for the suppression of water and compounds with high molecular mass. For data processing, Chenomx NMR Suit 7.1 professional with the Chenomx $600 \mathrm{MHz}$ library database were used (Chenomx Inc., Edmonton, AB, Canada). The bin size for spectra was $0.001 \mathrm{ppm}$. The binning data were normalized to the total area. PCA, partial least-squares discriminant analysis (PLS-DA), and orthogonal partial least-squares discriminant analysis (OPLS-DA) were performed using SIMCA-P+ 12.0 (Umetrics, Malmö, Sweden). 
For visualization of VIP scores of metabolites and Metabolic Set Enrichment Analysis, web-based software MetaboAnalyst 3.0 (http:/ / www.metaboanalyst.ca) was used.

\subsection{Pathway Enrichment Analysis}

Integrated Molecular Pathway Level Analysis (IMPaLa, http://impala.molgen.mpg.de/) was used to specify the pathways that are affected by SpD. Only VIP $>1.0$ metabolites and Log2(FC) $>1.2$ proteins were considered. Search Tool for the Retrieval of Interacting Genes/Proteins (STRING, https://string-db.org) and Cytoscape (downloaded at https:// cytoscape.org) were used for clustering molecular networks.

\section{Conclusions}

The present study investigated the effect of SpD on doxorubicin-treated cardiomyocytes through an integration of metabolic and proteomic analyses. Univariate and multivariate analyses of ${ }^{1} \mathrm{H}-\mathrm{NMR}$ spectroscopy data identified the potentially affected metabolites and groups of proteins from SpD-treated cardiomyocytes. Based on the ${ }^{1} \mathrm{H}-\mathrm{NMR}$ data, $\mathrm{SpD}$ increased glutathione, which regulates intracellular ROS stress. In addition, SpD treatment increased cytosolic and mitochondrial ATP production in cardiomyocytes, which was significantly correlated with increased lactate and decreased acetate levels. Co-treatment with SpD protected doxorubicin-treated cardiomyocytes, reducing the mitochondrial damage of doxorubicin. In contrast, $\mathrm{SpD}$ did not inhibit the cytotoxicity of doxorubicin in cancer cells. The integrated metabolomics and proteomics data suggest the involvement of the Akt/mTOR signaling pathway by which SpD might protect cardiomyocytes (Table 3). However, further study is still needed to verify these relationships.

Supplementary Materials: The following are available online at http:/ /www.mdpi.com/1660-3397/17/1/2/s1, Figure S1. Spinochrome D (SpD) showed no harmful effect on H9c2 rat cardiac cells. H9c2 rat embryonic cardiomyocytes were treated with $0-200 \mu \mathrm{M}$ of SpD for $24 \mathrm{~h}(2 \times 104$ cells/well, 96 -well plates). The cell viability was measured using CCK-8 assay. SpD did not affect on the cell viability of cardiomyocytes. * mark indicates $p<0.05$ compared with control. Figure S2. (A) PLS-DA from metabolites of SpD treated AC16 cells. (B) VIP $>0.1$ metabolites from SpD treated AC16 cells from PLS-DA. Figure S3. OPLS-DA from metabolites of SpD treated AC16 cells $(\mathrm{R} 2 \mathrm{X}=0.333 ; \mathrm{R} 2 \mathrm{Y}=0.937 ; \mathrm{Q} 2=0.597)$. Figure S4. Metabolite sets enrichment overview in $\mathrm{SpD}$ treated AC16 cells. Table S1. Genes and metabolites specified for the assigned pathways. Figure S5. STRING analysis revealed that metabolism associated proteins forms clusters around mitochondria (marked as red circles). Figure S6. Spinochrome D (SpD) showed enhanced antioxidant capacity compared with echinochrome A in AC16 and H9c2 cells. (A) SpD and echinochrome A showed no harmful effect on AC16 cells $(2 \times 104$ cells /well, 96-well plate, $24 \mathrm{~h}$ ). (B) SpD and echinochrome A protected AC16 cells against the cytotoxicity of doxorubicin. (C) SpD showed statistically enhanced antioxidant activity compared with echinochrome A. SpD produced enhanced ATP production in (D) AC16 cells and (E) H9c2 cells compared with echinochrome A. (F) SpD and echinochrome A showed enhanced OCR in AC16 cells. * mark indicates $p<0.05$ compared with control. Figure S7. SpD did not inhibit the cytotoxicity of doxorubicin. (A) Mitochondrial membrane potential and mitochondrial calcium was visualized using TMRE and rhod-2 staining in MCF-7 cells. Doxorubicin decreased TMRE intensity and increased rhod-2 intensity in dose-dependent manner. The co-treatment of $\mathrm{SpD}(10 \mu \mathrm{M})$ did not affect doxorubicin-induced tendency of fluorescence intensity. (B) The fluorescence was measured using fluorescence spectrometer. $\mathrm{SpD}$ co-treatment did not affect the intensity of TMRE, rhod-2, and DCF-DA in MCF-7 cells. (C) TMRE and rhod-2 fluorescence images from HeLa cells with doxorubicin/SpD. (D) The fluorescence measures indicated that SpD did not affect the intensity of TMRE, rhod-2, and DCF-DA in HeLa cells. Figure S8. SpD inhibited cell migration of cancer cells. $2 \times 104$ cells of MCF-7 and HeLa were plated in 25-well cell culture plates and scratch wounds were made with $200 \mu \mathrm{L}$ pipet tips. SpD was treated in 10-200 $\mu \mathrm{M}$ concentrations and incubated for $24 \mathrm{~h}$. Figure S9. Total glutathione and ratio of reduced glutathione to oxidized glutathione (GSH/GSSG). (A) Total glutathione ratio (\% of control) from SpD treated AC16 cells. (B) Ratio of reduced glutathione (GSH) to oxidized (GSSG) glutathione normalized by total glutathione concentration from control. The GSH/GSSG assay was measured using GSH/GSSG-Glo ${ }^{\mathrm{TM}}$ Assay (Promega, WI, USA) according to the product's manual. * and ** mark indicates $p<0.05, p<0.01$ compared with control, respectively. Supplementary Information 2 lists all proteins detected by mass-spectrometry of SpD treated AC16 cells.

Author Contributions: C.S.Y. and H.K.K. conducted the experiments, tests, and data analyses. N.P.M., E.A.V., and S.A.F. isolated and purified the SpD and provided advice for the omics analysis. C.S.Y., H.K.K., V.A.S., and J.H. summarized the work and wrote the manuscript.

Funding: This research was funded by the Ministry of Education, Science, and Technology (2010-0020224, 2018R1D1A1A09081767, and 2017K1A3A1A49070056). 
Acknowledgments: This study was supported by grants from the Priority Research Centers Program, Basic Science Research Program, and International Research \& Development Program through the National Research Foundation of Korea (NRF). The study was carried out under support of the Ministry of Education and Science of the Russian Federation (RFMEFI61317X0076) using the equipment of the Collective Facilities Center (The Far Eastern Center for Structural Molecular Research (NMR/MS) PIBOC FEB RAS).

Conflicts of Interest: The authors declare no conflict of interest.

\section{References}

1. Lebedev, A.V.; Levitskaya, E.L.; Tikhonova, E.V.; Ivanova, M.V. Antioxidant properties, autooxidation, and mutagenic activity of echinochrome a compared with its etherified derivative. Biochemistry 2001, 66, 885-893. [PubMed]

2. Lebedev, A.V.; Ivanova, M.V.; Levitsky, D.O. Echinochrome, a naturally occurring iron chelator and free radical scavenger in artificial and natural membrane systems. Life Sci. 2005, 76, 863-875. [CrossRef] [PubMed]

3. Jeong, S.H.; Kim, H.K.; Song, I.S.; Lee, S.J.; Ko, K.S.; Rhee, B.D.; Kim, N.; Mishchenko, N.P.; Fedoryev, S.A.; Stonik, V.A.; et al. Echinochrome A protects mitochondrial function in cardiomyocytes against cardiotoxic drugs. Mar. Drugs 2014, 12, 2922-2936. [CrossRef]

4. Pozharitskaya, O.N.; Shikov, A.N.; Makarova, M.N.; Ivanova, S.A.; Kosman, V.M.; Makarov, V.G.; Bazgier, V.; Berka, K.; Otyepka, M.; Ulrichova, J. Antiallergic effects of pigments isolated from green sea urchin (Strongylocentrotus droebachiensis) shells. Planta Med. 2013, 79, 1698-1704. [CrossRef]

5. Anderson, H.A.; Mathieson, J.W.; Thomson, R.H. Distribution of spinochrome pigments in echinoids. Comp. Biochem. Physiol. 1969, 28, 333-345. [CrossRef]

6. Nagaoka, S.; Shiraishi, J.; Utsuyama, M.; Seki, S.; Takemura, T.; Kitagawa, M.; Sawabe, M.; Takubo, K.; Hirokawa, K. Poor prognosis of colorectal cancer in patients over 80 years old is associated with down-regulation of tumor suppressor genes. J. Clin. Gastroenterol. 2003, 37, 48-54. [CrossRef] [PubMed]

7. Balaneva, N.N.; Shestak, O.P.; Anufriev, V.F.; Novikov, V.L. Synthesis of Spinochrome D, A Metabolite of Various Sea-Urchin Species. Chem. Nat. Compd. 2016, 52, 213-217. [CrossRef]

8. Arcamone, F.; Cassinelli, G.; Fantini, G.; Grein, A.; Orezzi, P.; Pol, C.; Spalla, C. Adriamycin, 14-hydroxydaunomycin, a new antitumor antibiotic from S. peucetius var. caesius. Biotechnol. Bioeng. 1969, 11, 1101-1110. [CrossRef]

9. Cortes-Funes, H.; Coronado, C. Role of anthracyclines in the era of targeted therapy. Cardiovasc. Toxicol. 2007, 7, 56-60. [CrossRef]

10. Takemura, G.; Fujiwara, H. Doxorubicin-induced cardiomyopathy from the cardiotoxic mechanisms to management. Prog. Cardiovasc. Dis. 2007, 49, 330-352. [CrossRef]

11. Bachur, N.R.; Gee, M.V.; Friedman, R.D. Nuclear catalyzed antibiotic free radical formation. Cancer Res. 1982, 42, 1078-1081. [PubMed]

12. Sinha, B.K.; Katki, A.G.; Batist, G.; Cowan, K.H.; Myers, C.E. Adriamycin-stimulated hydroxyl radical formation in human breast tumor cells. Biochem. Pharmacol. 1987, 36, 793-796. [CrossRef]

13. Lefrak, E.A.; Pitha, J.; Rosenheim, S.; Gottlieb, J.A. A clinicopathologic analysis of adriamycin cardiotoxicity. Cancer 1973, 32, 302-314. [CrossRef]

14. Franco, Y.L.; Vaidya, T.R.; Ait-Oudhia, S. Anticancer and cardio-protective effects of liposomal doxorubicin in the treatment of breast cancer. Breast Cancer 2018, 10, 131-141. [CrossRef]

15. Thorn, C.F.; Oshiro, C.; Marsh, S.; Hernandez-Boussard, T.; McLeod, H.; Klein, T.E.; Altman, R.B. Doxorubicin pathways: Pharmacodynamics and adverse effects. Pharmacogenet. Genom. 2011, 21, 440-446. [CrossRef]

16. Siveski-Iliskovic, N.; Hill, M.; Chow, D.A.; Singal, P.K. Probucol protects against adriamycin cardiomyopathy without interfering with its antitumor effect. Circulation 1995, 91, 10-15. [CrossRef]

17. Mohamed, E.A.; Kassem, H.H. Protective effect of nebivolol on doxorubicin-induced cardiotoxicity in rats. Arch. Med. Sci. 2018, 14, 1450-1458. [CrossRef]

18. Studneva, I.; Palkeeva, M.; Veselova, O.; Molokoedov, A.; Ovchinnikov, M.; Sidorova, M.; Pisarenko, O. Protective Effects of a Novel Agonist of Galanin Receptors Against Doxorubicin-Induced Cardiotoxicity in Rats. Cardiovasc. Toxicol. 2018, 1-11. [CrossRef] [PubMed]

19. Pilco-Ferreto, N.; Calaf, G.M. Influence of doxorubicin on apoptosis and oxidative stress in breast cancer cell lines. Int. J. Oncol. 2016, 49, 753-762. [CrossRef] 
20. Agafonova, I.G.; Kotel'nikov, V.N.; Mischenko, N.P.; Kolosova, N.G. Evaluation of effects of histochrome and mexidol on structural and functional characteristics of the brain in senescence-accelerated OXYS rats by magnetic resonance imaging. Bull. Exp. Biol. Med. 2011, 150, 739-743. [CrossRef]

21. Al-Ghamdi, S.S. Time and dose dependent study of doxorubicin induced DU-145 cytotoxicity. Drug Metab. Lett. 2008, 2, 47-50. [CrossRef]

22. Wang, S.; Konorev, E.A.; Kotamraju, S.; Joseph, J.; Kalivendi, S.; Kalyanaraman, B. Doxorubicin induces apoptosis in normal and tumor cells via distinctly different mechanisms. intermediacy of $\mathrm{H}(2) \mathrm{O}(2)$ - and p53-dependent pathways. J. Biol. Chem. 2004, 279, 25535-25543. [CrossRef]

23. Magnelli, L.; Cinelli, M.; Chiarugi, V. Phorbol esters attenuate the expression of p53 in cells treated with doxorubicin and protect TS-P53/K562 from apoptosis. Biochem. Biophys. Res. Commun. 1995, 215, 641-645. [CrossRef] [PubMed]

24. McCurrach, M.E.; Connor, T.M.; Knudson, C.M.; Korsmeyer, S.J.; Lowe, S.W. bax-deficiency promotes drug resistance and oncogenic transformation by attenuating p53-dependent apoptosis. Proc. Natl. Acad. Sci. USA 1997, 94, 2345-2349. [CrossRef] [PubMed]

25. Worley, B.; Powers, R. Multivariate Analysis in Metabolomics. Curr. Metab. 2013, 1, 92-107.

26. Kotze, H.L.; Armitage, E.G.; Sharkey, K.J.; Allwood, J.W.; Dunn, W.B.; Williams, K.J.; Goodacre, R. A novel untargeted metabolomics correlation-based network analysis incorporating human metabolic reconstructions. BMC Syst. Biol. 2013, 7, 107. [CrossRef]

27. Hosios, A.M.; Vander Heiden, M.G. Acetate metabolism in cancer cells. Cancer Metab. 2014, 2, 27. [CrossRef]

28. Knowles, S.E.; Jarrett, I.G.; Filsell, O.H.; Ballard, F.J. Production and utilization of acetate in mammals. Biochem. J. 1974, 142, 401-411. [CrossRef]

29. Rajaram, R.D.; Dissard, R.; Jaquet, V.; de Seigneux, S. Potential benefits and harms of NADPH oxidase type 4 in the kidneys and cardiovascular system. Nephrol. Dial. Transpl. 2018. [CrossRef]

30. Wu, H.; Huang, S.; Chen, Z.; Liu, W.; Zhou, X.; Zhang, D. Hypoxia-induced autophagy contributes to the invasion of salivary adenoid cystic carcinoma through the HIF-1alpha/BNIP3 signaling pathway. Mol. Med. Rep. 2015, 12, 6467-6474. [CrossRef]

31. Kraskiewicz, H.; FitzGerald, U. Partial XBP1 knockdown does not affect viability of oligodendrocyte precursor cells exposed to new models of hypoxia and ischemia in vitro. J. Neurosci. Res. 2011, 89, 661-673. [CrossRef] [PubMed]

32. Chhunchha, B.; Fatma, N.; Kubo, E.; Rai, P.; Singh, S.P.; Singh, D.P. Curcumin abates hypoxia-induced oxidative stress based-ER stress-mediated cell death in mouse hippocampal cells (HT22) by controlling Prdx6 and NF-kappaB regulation. Am. J. Physiol. Cell Physiol. 2013, 304, C636-C655. [CrossRef] [PubMed]

33. Fakhruddin, S.; Alanazi, W.; Jackson, K.E. Diabetes-Induced Reactive Oxygen Species: Mechanism of Their Generation and Role in Renal Injury. J. Diabetes Res. 2017, 2017, 8379327. [CrossRef]

34. Volpe, C.M.O.; Villar-Delfino, P.H.; Dos Anjos, P.M.F.; Nogueira-Machado, J.A. Cellular death, reactive oxygen species (ROS) and diabetic complications. Cell Death Dis. 2018, 9, 119. [CrossRef]

35. Pang, Y.; Hunton, D.L.; Bounelis, P.; Marchase, R.B. Hyperglycemia inhibits capacitative calcium entry and hypertrophy in neonatal cardiomyocytes. Diabetes 2002, 51, 3461-3467. [CrossRef] [PubMed]

36. Feng, N.; Anderson, M.E. CaMKII is a nodal signal for multiple programmed cell death pathways in heart. J. Mol. Cell Cardiol. 2017, 103, 102-109. [CrossRef]

37. Singh, R.M.; Waqar, T.; Howarth, F.C.; Adeghate, E.; Bidasee, K.; Singh, J. Hyperglycemia-induced cardiac contractile dysfunction in the diabetic heart. Heart Fail. Rev. 2018, 23, 37-54. [CrossRef]

38. Adams, J.W.; Pagel, A.L.; Means, C.K.; Oksenberg, D.; Armstrong, R.C.; Brown, J.H. Cardiomyocyte apoptosis induced by Galphaq signaling is mediated by permeability transition pore formation and activation of the mitochondrial death pathway. Circ. Res. 2000, 87, 1180-1187. [CrossRef] [PubMed] 
39. Diogo, C.V.; Suski, J.M.; Lebiedzinska, M.; Karkucinska-Wieckowska, A.; Wojtala, A.; Pronicki, M.; Duszynski, J.; Pinton, P.; Portincasa, P.; Oliveira, P.J.; et al. Cardiac mitochondrial dysfunction during hyperglycemia-the role of oxidative stress and p66Shc signaling. Int. J. Biochem. Cell Biol. 2013, 45, 114-122. [CrossRef]

40. Lane, R.S.; Fu, Y.; Matsuzaki, S.; Kinter, M.; Humphries, K.M.; Griffin, T.M. Mitochondrial respiration and redox coupling in articular chondrocytes. Arthritis Res. Ther. 2015, 17, 54. [CrossRef]

41. Aguer, C.; Gambarotta, D.; Mailloux, R.J.; Moffat, C.; Dent, R.; McPherson, R.; Harper, M.E. Galactose enhances oxidative metabolism and reveals mitochondrial dysfunction in human primary muscle cells. PLOS ONE 2011, 6, e28536. [CrossRef] [PubMed]

42. Kase, E.T.; Nikolic, N.; Bakke, S.S.; Bogen, K.K.; Aas, V.; Thoresen, G.H.; Rustan, A.C. Remodeling of oxidative energy metabolism by galactose improves glucose handling and metabolic switching in human skeletal muscle cells. PLoS ONE 2013, 8, e59972. [CrossRef]

43. Kuznetsov, A.V.; Margreiter, R.; Amberger, A.; Saks, V.; Grimm, M. Changes in mitochondrial redox state, membrane potential and calcium precede mitochondrial dysfunction in doxorubicin-induced cell death. Biochim. Biophys. Acta 2011, 1813, 1144-1152. [CrossRef] [PubMed]

44. Mishchenko, N.P.; Vasileva, E.A.; Fedoreev, S.A. Mirabiquinone, a new unsymmetrical binaphthoquinone from the sea urchin Scaphechinus mirabilis. Tetrahedron Lett. 2014, 55, 5967-5969. [CrossRef]

45. Vasileva, E.A.; Mishchenko, N.P.; Vo, H.M.; Bui, L.M.; Denisenko, V.A.; Fedoreyev, S.A. Quinoid pigments from the sea urchin Astropyga radiata. Chem. Nat. Compd. 2017, 53, 356-358. [CrossRef]

(C) 2018 by the authors. Licensee MDPI, Basel, Switzerland. This article is an open access article distributed under the terms and conditions of the Creative Commons Attribution (CC BY) license (http:/ / creativecommons.org/licenses/by/4.0/). 